\title{
Gross and histopathologic diagnoses from North Atlantic right whale Eubalaena glacialis mortalities between 2003 and 2018
}

\author{
S. M. Sharp ${ }^{1, *}$, W. A. McLellan, D. S. Rotstein, A. M. Costidis, S. G. Barco, K. Durham, \\ T. D. Pitchford, K. A. Jackson, P.-Y. Daoust, T. Wimmer, E. L. Couture, L. Bourque, \\ T. Frasier, B. Frasier, D. Fauquier, T. K. Rowles, P. K. Hamilton, H. Pettis, M. J. Moore \\ ${ }^{1}$ International Fund for Animal Welfare, Yarmouth Port, MA 02675, USA \\ Addresses for other authors are given in the supplements at www.int-res.com/articles/suppl/d135p001_supp.pdf
}

\begin{abstract}
Seventy mortalities of North Atlantic right whales Eubalaena glacialis (NARW) were documented between 2003 and 2018 from Florida, USA, to the Gulf of St. Lawrence, Canada. These included 30 adults, 14 juveniles, 10 calves, and 16 of unknown age class. Females represented $65.5 \%$ (19/29) of knownsex adults. Fourteen cases had photos only; 56 carcasses received external examinations, 44 of which were also necropsied. Cause of death was determined in 43 cases, of which $38(88.4 \%)$ were due to anthropogenic trauma: $22(57.9 \%)$ from entanglement, and $16(42.1 \%)$ from vessel strike. Gross and histopathologic lesions associated with entanglement were often severe and included deep lacerations caused by constricting line wraps around the flippers, flukes, and head/mouth; baleen plate mutilation; chronic extensive bone lesions from impinging line, and traumatic scoliosis resulting in compromised mobility in a calf. Chronically entangled whales were often in poor body condition and had increased cyamid burden, reflecting compromised health. Vessel strike blunt force injuries included skull and vertebral fractures, blubber and muscle contusions, and large blood clots. Propeller-induced wounds often caused extensive damage to blubber, muscle, viscera, and bone. Overall prevalence of NARW entanglement mortalities increased from $21 \%(1970-2002)$ to $51 \%$ during this study period. This demonstrates that despite mitigation efforts, entanglements and vessel strikes continue to inflict profound physical trauma and suffering on individual NARWs. These cumulative mortalities are also unsustainable at the population level, so urgent and aggressive intervention is needed to end anthropogenic mortality in this critically endangered species.
\end{abstract}

*Corresponding author: ssharp@ifaw.org

${ }^{\S}$ Corrections were made after publication. For details see www.int-res.com/abstracts/dao/v135/n1/c_p1-31/

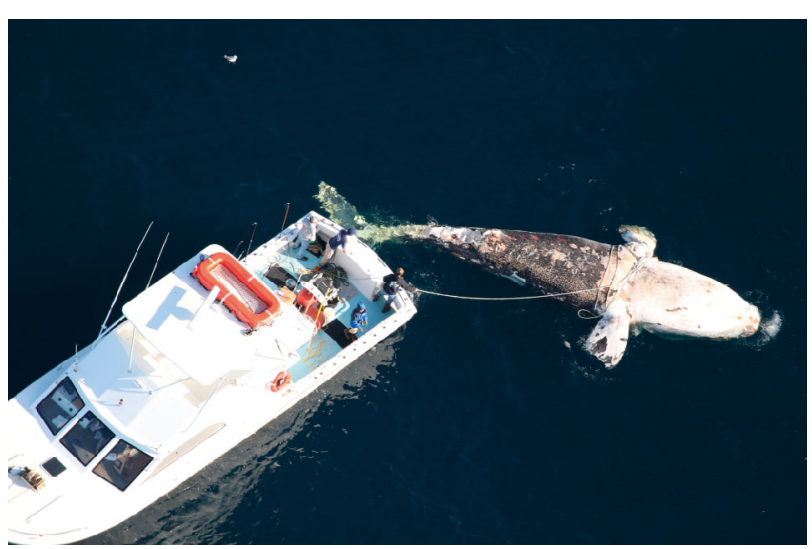

North Atlantic right whale carcass found chronically entangled in fishing gear $\sim 60$ miles off the Virginia coast, and later towed to shore for necropsy. Investigating whale carcasses to determine cause of death requires specialized skills, logistics, and dedicated funding.

Photo: Sea to Shore Alliance (NOAA permit \#20556)

KEY WORDS: North Atlantic right whale Eubalaena glacialis · Mortality · Entanglement Vessel strike $\cdot$ Necropsy $\cdot$ Pathology $\cdot$ Morphology

\section{INTRODUCTION}

The North Atlantic right whale Eubalaena glacialis (NARW) is one of the most endangered large whale species in the world (listed as 'Endangered' on the IUCN Red List; Cooke 2018). NARWs are found primarily within the northwest Atlantic Ocean from Florida, USA, to the Gulf of St. Lawrence, Canada (Knowlton et al. 1992, Khan et al. 2016). By the early

(C) The authors 2019. Open Access under Creative Commons by Attribution Licence. Use, distribution and reproduction are unrestricted. Authors and original publication must be credited.

Publisher: Inter-Research · www.int-res.com 
20th century, all 3 right whale species (North Atlantic, North Pacific, and southern) had been hunted to near extinction by the commercial whaling industry (Reeves 2001). International protections for all right whale species were first instituted over $80 \mathrm{yr}$ ago. NARWs have been legally protected under the US Endangered Species Act and Marine Mammal Protection Act for nearly $50 \mathrm{yr}$ and the Canadian Species at Risk Act for 15 yr (DFO 2014). Despite this long-term protection, NARWs have experienced no appreciable recovery, in contrast to their southern hemisphere counterpart, southern right whales $E$. australis (Cooke et al. 2015, Bannister et al. 2016, Findlay et al. 2017, Corkeron et al. 2018).

While a period of population growth for NARWs was documented around the turn of this century, in 2010 NARWs started to decrease in number once again (Pace et al. 2017, Pettis et al. 2018). This decline has been attributed to a variety of factors, primarily low reproductive rates (Kraus et al. 2001, Pettis et al. 2018) and high mortality rates caused by entanglement in fishing gear and vessel strikes (Kraus 1990, Caswell et al. 1999, Knowlton \& Kraus 2001, Moore et al. 2004, van der Hoop et al. 2013, Corkeron et al. 2018, Kenney 2018). At the end of 2017, between 392 and 433 (95\% confidence range; best estimate $=411$ ) NARWs remained in the population (Pettis et al. 2018, based on the methodology of Pace et al. 2017). Among them, only 90 were likely adult females (Hayes et al. 2018a), the most crucial demographic for reproduction. If the present downward trend continues, the population could become functionally extinct within a few decades. Additionally, NARW reproductive success has been linked to climate-associated ecosystem regime shifts, which are currently unfavorable for the species (MeyerGutbrod \& Greene 2018). Neither the current environmental conditions nor the unpredictability of future climate trends were accounted for in the most recent population models (Pace et al. 2017), suggesting that population decline may proceed even more rapidly than projected.

NARW reproductive trends demonstrate increasing calving intervals, declining numbers of first-time dams (calving females), and declining percentage of available dams that calve (Kraus et al. 2001, Pettis et al. 2017a). In fact, the annual rate of increase of the NARW population between 1990 and 2016 was $2 \%$ (including the decline in abundance observed since 2010), which is only one-third that of their southernhemisphere counterparts (Corkeron et al. 2018). While the etiology of poor population recovery in the NARW population, including factors such as repro- ductive failure, is uncertain, anthropogenic stressors such as sub-lethal chronic entanglement and ocean noise are suspected to be contributing factors (Tyack 2008, Rolland et al. 2012, van der Hoop et al. 2016). Climate-associated changes in prey availability (Meyer-Gutbrod \& Greene 2014, Meyer-Gutbrod et al. 2015) and poorer overall health and body condition in adult females (Rolland et al. 2016, Pettis et al. 2017 b) may also be reducing fecundity.

In an effort to mitigate direct anthropogenic mortalities, the US and Canadian governments have implemented large-scale management efforts over the past 20 yr. Measures to reduce vessel strike mortalities included shifts in traffic separation schemes in the Bay of Fundy (2003) and Boston, MA (2007); the designation of the Roseway Basin (2007) and Great South Channel (2009) Areas to be Avoided; and the US ship speed restriction rule (2008), which established seasonal and dynamic management areas (NMFS 2008, van der Hoop et al. 2013). The latter effort resulted in decreased vessel-strike mortalities within seasonal management areas in the USA, but increased vessel strikes outside of them (Laist et al. 2014, van der Hoop et al. 2015). In addition, fishing gear modifications have been implemented in the USA by the Atlantic Large Whale Take Reduction Plan since 1997 in an effort to better understand and reduce large whale entanglements. These measures include the incorporation of weak links into fishing gear configurations, seasonal fishery closures, gear marking, sinking groundline (2009), establishment of a minimum number of traps per trawl (vertical line rule, 2015), and ghost gear clean ups (NMFS 2014, Hayes et al. 2018a). Unfortunately, these mitigations have not been effective in reducing the number of entanglement events for large whales (Pace et al. 2014, Hayes et al. 2018a), and the severity of entanglements has actually increased in recent years (Knowlton et al. 2012). The Government of Canada also recently implemented shipping and fishing regulations in response to the unprecedented deaths of 12 NARWs in Canadian waters in 2017. These cases are part of an ongoing unusual mortality event (NMFS 2019).

NARW mortality data from 1970-2002 were previously summarized by Moore et al. (2004). During that 32 yr period, 54 NARW mortalities were documented, and cause of death was established in 19 cases. Of those, 14 deaths were due to vessel strikes (74\%), 4 to entanglements $(21 \%)$, and 1 to perinatal death (5\%). The current review summarizes gross and histopathologic findings from NARW deaths that occurred in the subsequent $16 \mathrm{yr}$ period, i.e. 2003-2018. 


\section{METHODS}

Between 2003 and 2018, NARW mortalities were reported to marine mammal stranding network agencies, government officials, and whale researchers in the USA and Canada (see Acknowledgements). Data were entered into standardized fields in a dedicated Microsoft Access necropsy database for the North Atlantic Right Whale Consortium (NARWC 2018a). Varying levels of data were available on each case due to sighting circumstance, location of carcass, environmental conditions, available personnel, and carcass condition. To be considered a confirmed NARW death, a minimum of carcass location and photograph(s) enabling species identification were required. Drift analyses, condition code timeline, and distinguishing marks were employed to avoid double-counting carcasses that were not able to be brought to shore for necropsy and disposal.

\subsection{Carcass documentation and necropsy}

In some cases, NARW carcasses were confirmed but never relocated after the initial report. In other cases, documentation of floating carcasses was limited to an at-sea examination, with or without limited sampling. When carcasses stranded or were towed ashore, a thorough examination was conducted barring adverse environmental or logistical conditions. A decomposition code of 1-5 was assigned based on the definitions in Geraci \& Lounsbury (2005). Morphometrics were obtained and a necropsy was conducted following the protocol outlined by McLellan et al. (2004) whenever feasible. A correction factor of $-9 \%$ of the measured length (Fortune et al. 2012) was employed to obtain a corrected total straight length for animals that were measured after being towed at sea and/or hauled onto a beach. Weights of the whale carcasses were obtained in a variety of ways: by using a vessel travel lift to weigh the whale as it was hauled out of the water; by net weight determination of whales placed on a flatbed truck and transported to a weigh station prior to necropsy by subtracting the weight of the empty vehicle/trailer from the weight with the whale; or by corrected weight determination when the soft tissues and skeleton were weighed separately after the necropsy by adding $6.8 \%$ to that measurement to account for un-weighed fluid losses (calculated from McLellan et al. 2004, Moore et al. 2004). In one case, the post-necropsy tissues and skeleton were weighed without the baleen racks and an additional estimated $250 \mathrm{~kg}$ was added to the total weight to account for this missing tissue. Body condition in stranded right whales has not been documented in a standardized format over the years. The most frequently used descriptive terms in necropsy reports were 'robust/good,' 'thin/poor,' and 'emaciated.' In some cases, only blubber thickness measurements were recorded, with no subjective body condition assessment included in the gross necropsy report.

Identification photographs were obtained when available for comparison to the NARWC identification database (NARWC 2018b) enabling carcasses to be matched to previously documented or known living individuals. Samples (most often skin, post-cranial, or occipital condyle bone core) were obtained to assist with individual identification on a molecular level to support photographic identification or in lieu of it when identification images were not available. Genetic samples were analyzed though combined efforts at Trent University (Peterborough, Ontario, Canada) and Saint Mary's University (Halifax, Nova Scotia, Canada). When sample quality allowed, individual-specific genetic profiles were obtained for each sample based on high-resolution genetic profiling protocols (sequencing a portion of the mitochondrial control region, molecular sex determination, and genotype analysis at 35 microsatellite loci) as described by Frasier et al. (2013). For samples where the DNA was highly degraded, mitochondrial sequencing and molecular sexing were still conducted, but only the 5 most polymorphic loci were typed, using modified protocols specific for the analysis of highly degraded DNA (McLeod et al. 2010). More loci were added until adequate resolution was obtained for individual identification, or if it was deemed that the DNA was too degraded to obtain reliable results. These results were then compared to the NARW genetic database, which contains genetic profiles for more than $75 \%$ of all identified NARWs (Frasier et al. 2009) and is curated through Trent and Saint Mary's Universities.

Age classes were defined as follows for cataloged whales; calf: $1 \mathrm{~d}$ to $1 \mathrm{yr}$; juvenile $>1$ to $<9 \mathrm{yr}$ or until the year before they calve if it occurs before they are 10; and adult $\geq 9$ yr (Hamilton et al. 1998, Rolland et al. 2005). For carcasses of unknown ages, age class was assigned based on necropsy findings (mature/ immature status of gonads) and/or actual or corrected total straight length according to Moore et al. (2004), where calf: $<900 \mathrm{~cm}$; juvenile: $>1000$ and $\leq 1200 \mathrm{~cm}$; and adult $>1400 \mathrm{~cm}$; for any lengths falling outside these ranges, age class cannot be determined (CBD). 
Comprehensive internal and external sampling was performed to the extent possible on examined whales, but was occasionally limited by advanced decomposition and/or logistical constraints. Various tissues were collected for analyses including advanced diagnostic imaging (CT), histopathological examination (preserved in 10\% neutral buffered formalin), bacterial and viral testing (frozen at $-80^{\circ} \mathrm{C}$ dry and/or stored in RNA stabilizing solution), contaminant, stress hormone, and biotoxin analyses (frozen at -20 or $-80^{\circ} \mathrm{C}$ ), and life history information (frozen at -20 or $-80^{\circ} \mathrm{C}$ ).

\subsection{Case reviews}

This retrospective case review study included all available data from confirmed NARW mortalities between 2003 and 2018, which were entered into standardized fields in the NARWC necropsy database (NARWC 2018a) and distilled into short case summaries with representative gross images. Each summary includes a brief case history (date reported, location of initial sighting, towed at sea/hauled on beach), necropsy geographic location, brief carcass description (decomposition code, \% skin present, evidence of bloating, presence of baleen), signalment (age or age class, sex), major gross and histopathologic findings, ancillary diagnostic findings, ultimate and proximate cause of death, relevant incidental findings, and a discussion regarding timeline and interpretation of findings. Each case summary was reviewed by the primary case prosector for accuracy.

In many cases, primary prosectors had assigned a cause of death (COD) for the whale in the final necropsy report. All CODs were standardized based on a commonly used veterinary pathophysiological categorization of diseases (adapted DAMNIT-V categorization; Table 1). Proximate COD is defined as the underlying condition(s) that started the chain of events leading to death (e.g. 'Trauma-propeller trauma vessel strike'). Ultimate COD is defined as the condition that caused the animal to die at that place and time (e.g. 'Trauma-hemorrhage/hypovolemic shock' as a result of a proximate COD of 'Trauma - propeller trauma vessel strike'). In many instances, ultimate COD is inferred from the severity and location of lesions rather than as a morphological diagnosis. For cases where the established COD was not specified to be proximate or ultimate or was not assigned, the primary author categorized proximate and ultimate CODs based on the available data and submitted them to the primary prosector for approval. Degree of confidence for ultimate and proximate CODs were scored according to definitions developed by Moore et al. (2013). Moore et al. (2004, 2013) classified propeller trauma as 'sharp' and trauma from hull parts as 'blunt.' However, a recent discussion of propeller trauma (Semeraro et al. 2012) suggests that propeller blade edges are not truly sharp, and that the resulting trauma can be both 'sharp' and 'blunt' at times. Thus, we describe any trauma inflicted by a propeller as 'propeller-induced trauma.'

\subsection{Analysis}

For all morphometric analyses, only whales with actual or corrected total straight lengths (not estimated), actual or corrected weights (not estimated), and known actual or minimum age (based on sightings history) were included. All morphometric data 
were validated against the original datasheets for accuracy, including whether the weights and lengths were actual or estimated. Total straight length, weight, and age were compared to establish length-weight curves, age-length curves, and age-weight curves. Fluke width and anterior flipper edge length, as defined in the morphometrics data sheet, were regressed on total straight length to facilitate length extrapolations for future decomposed or incomplete carcasses where total straight length is not available. All curves were graphed and regressed in MedCalc for Windows, version 18.10.2 (MedCalc Software), using logarithmic, exponential, or geometric equations as best-fit analysis indicated for each dataset. In order to increase sample size, all regressions were performed with the complete NARW mortality dataset from 1970-2018 archived in the NARWC necropsy database (NARWC 2018a) established by the Woods Hole Oceanographic Institution (WHOI) and currently maintained by the International Fund for Animal Welfare (IFAW). The mortality plots were generated using ArcMap 10.6.1 and the Albers Equal Area Conic projection (ESRI).

\section{RESULTS}

Between 2003 and 2018, 70 confirmed NARW mortalities were reported in US and Canadian waters (see Supplement 1, Table S1 for a complete list of carcasses). The average annual number of mortalities over the 16 yr study period was 4.4 , with an outlier peak in 2017 of 17 (range 1-17, SD 3.6) that was related to an ongoing unusual mortality event (see Section 4.3). Excluding the outlier year, the annual mean was 3.5 reported NARW deaths (range 1-6, SD 1.25). The majority of these cases were initially sighted floating at sea $(\mathrm{n}=51)$, while 16 were found stranded dead on shore and the remaining 3 cases stranded alive $(2$ calves and 1 juvenile). Of the 70 confirmed mortalities, 13 whales were not examined (only photographs and location data were available due to poor field conditions, offshore location, or other logistical limitations), 1 had an initial exam with no sampling, 1 had initial sampling with no exam, 11 were minimally examined and sampled (these included floating carcasses that were examined from vessels with no towing option, and stranded carcasses with minimal viscera due to advanced state of decomposition and/or in a remote location; data collected varied), and 44 were necropsied. Necropsied whales were fresh dead (Code 2, $\mathrm{n}=3$ ), moderately decomposed (Code $3, \mathrm{n}=20$ ), or in advanced decomposition (Code $4, \mathrm{n}=21$ ).

Sex was identified in 59/70 (84.3\%) cases and age class in 54/70 (77.1\%) cases; in 10 cases, neither age class nor sex could be determined either due to decomposition, scavenger damage, or lack of exam. There were 31 females, 28 males, and 11 whales of undetermined sex. More adult mortalities were documented $(\mathrm{n}=29)$ than juveniles $(\mathrm{n}=14)$ and calves $(n=10)$ combined. Adult females represented the largest overall demographic, comprising 19/29 $(65.5 \%)$ of the known-sex adult mortalities. Table 2 presents a summary of age class and sex. The majority of calves stranded prior to $2010(9 / 10,90 \%)$ while the majority of adults $(20 / 30,66.7 \%)$ and juveniles (10/15, 66.7\%) stranded between 2010 and 2018.

NARW mortalities were documented from the Atlantic coast of northeastern Florida (southernmost part of calving grounds, frequented in winter) to the northwestern coast of Newfoundland in the Gulf of St. Lawrence (northernmost part of commonly used feeding grounds, frequented in summer). A map of confirmed NARW mortalities from 2003 through 2018 with associated causes of death is provided in Fig. 1. Of the 70 confirmed mortalities, 23 occurred in Canada, 1 at the Canada/US border, and 46 in the USA. Four spatial mortality aggregations are subjectively evident, including 11 deaths in the southeastern USA (Georgia and Florida), 10 off North Carolina and Virginia, 17 off Massachusetts, and 15 deaths in the Gulf of St. Lawrence. It is also important to remember that location of entanglement death does not necessarily reflect the location where the whale became entangled, since whales are able to carry gear over long distances. Across all years, seasonal mortality peaks occurred in summer (June-August, $\mathrm{n}=27$ ) and winter (December-February, $\mathrm{n}=20$ ) with spring (March-May, $\mathrm{n}=12$ ) and fall (September-November, $\mathrm{n}=11$ ) having lower overall mortalities (Table 3 ). Deaths only occurred in the calving grounds (Florida

Table 2. Summary of age class and sex for all confirmed North Atlantic right whale mortalities 2003-2018 ( $\mathrm{n}=70$ )

\begin{tabular}{|lcccc}
\hline \multirow{2}{*}{ Age class } & \multicolumn{4}{c}{ Sex } \\
\cline { 2 - 5 } & Male & Female & Undetermined & Total \\
\hline Adult & 10 & 19 & 1 & 30 \\
Juvenile & 5 & 9 & 0 & 14 \\
Calf & 8 & 2 & 0 & 10 \\
Undetermined & 5 & 1 & 10 & 16 \\
Total & 28 & 31 & 11 & 70 \\
\hline
\end{tabular}




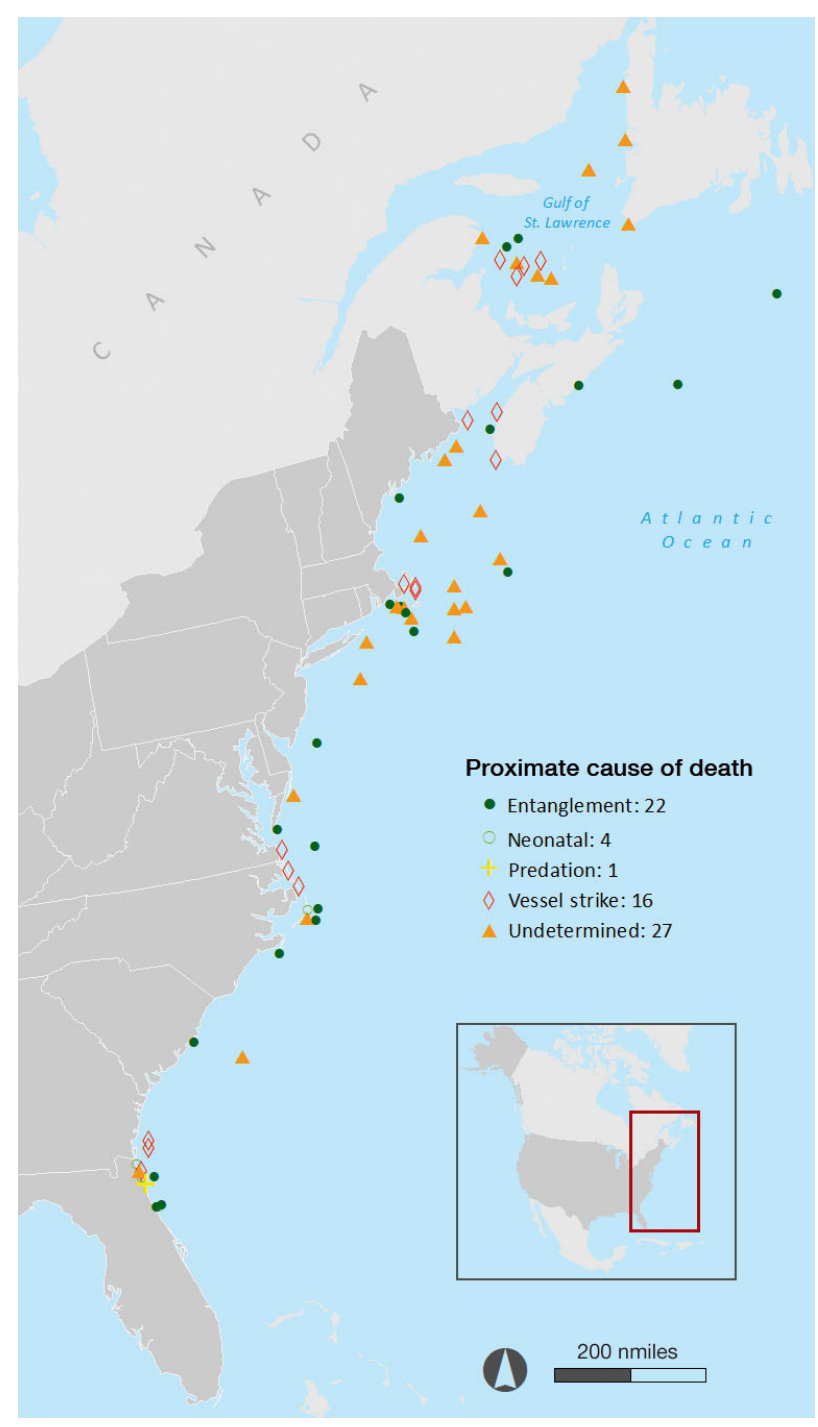

Fig. 1. North Atlantic right whale mortalities between 2003 and 2018, highlighting proximate cause of death. Entanglement deaths do not necessarily occur where the whale was initially entangled

and Georgia) during winter months, the majority of which were calves $(7 / 11,64 \%)$. The remaining 3 calves stranded in North Carolina (March and December) and Cape Cod (May). The majority of summer deaths occurred in Canadian waters $(n=19)$, and the majority of spring deaths occurred in midAtlantic waters (New York to South Carolina, $n=7$ ). Mortalities documented between Massachusetts and Maine were nearly equivalent in each season $(\mathrm{n}=4$ in winter, 5 in spring, 5 in summer, 6 in fall). A map of mortalities by season is provided in Fig. A1 in the Appendix.
Table 3. Temporospatial North Atlantic right whale mortality data 2003-2018 ( $\mathrm{n}=70)$. Mid-Atlantic includes New York through South Carolina. Seasons are defined as winter: December-February; spring: March-May; summer: JuneAugust; fall: September-November

\begin{tabular}{|lcccc|}
\hline Season & $\begin{array}{c}\text { Florida/ } \\
\text { Georgia }\end{array}$ & $\begin{array}{c}\text { Mid- } \\
\text { Atlantic }\end{array}$ & $\begin{array}{c}\text { Massachusetts } \\
\text { to Maine }\end{array}$ & Canada \\
\hline Winter & 11 & 5 & 4 & 0 \\
Spring & 0 & 7 & 5 & 0 \\
Summer & 0 & 3 & 5 & 19 \\
Fall & 0 & 1 & 6 & 4 \\
\hline
\end{tabular}

\subsection{Causes of mortality}

COD was determined in $43 / 70(61.4 \%)$ cases. The cause of the remaining 27 mortalities was undetermined due to advanced state of decomposition ( $\mathrm{n}=$ $10)$ or inability to fully examine the carcass $(n=17)$. Four whales that were not available for necropsy were determined through photographic evidence to have active, severe, and extensive line entanglements sufficient to assign entanglement-related CODs.

Natural CODs were found in 5/43 (11.6\%) cases, and only in calves (5/10 calves, 50\%). These CODs were largely attributed to perinatal complications such as stillbirth, dystocia, failure of passive transfer (immune compromise, diagnosed by low globulins on serum electrophoresis), and malnutrition due to either presumed maternal abandonment or developmental abnormalities within the gastrointestinal tract including a colic-like disorder (or both). The gross necropsy report of 1 young calf concluded that it died due to hemorrhage and hypovolemic shock as sequelae to shark predation (EgNEFL0904 / 3910), but the histopathology report was not available to provide further support for this conclusion (confidence level was limited to 'suspect'). Proximate and ultimate CODs are summarized in Table 4 for all 43 cases in which COD could be determined.

All 38 of the remaining cases for which COD could be determined died due to anthropogenic trauma. This includes all adults $(n=18)$, all juveniles $(n=9)$, 4 calves, and all NARWs of undetermined age class $(n=7)$. Sixteen NARWs died as a result of collisions with vessels (9 females, 7 males, see Sections 3.3.1 and 3.3.2), and 22 died due to entanglement in line (9 females, 10 males, and 3 undetermined sex, see Section 3.3.3). Six of the vessel strike cases had evidence of propeller-induced trauma, and 10 had blunt force trauma consistent with the impact of a vessel. Deaths due to vessel strike (blunt or propeller-induced 
3

ช ฮี

ปี

क्ष

急

ชิ

표

\begin{tabular}{|c|c|c|}
\hline 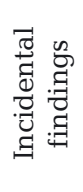 & 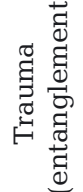 & 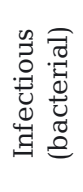 \\
\hline $\begin{array}{l}0 \\
0 \\
0 \\
0 \\
0 \\
0 \\
0 \\
0 \\
0\end{array}$ & $\begin{array}{l}0 \\
0 \\
0 \\
0 \\
0 \\
0\end{array}$ & 艺 \\
\hline
\end{tabular}

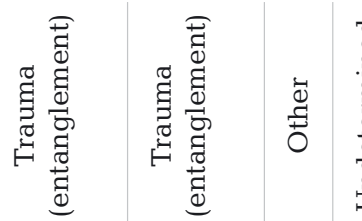

\begin{tabular}{l|l}
0 & 0 \\
0 & 0 \\
0 & 0 \\
0 & 0 \\
0 & 0
\end{tabular}

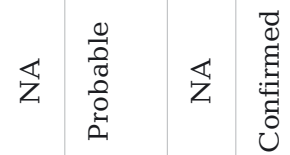

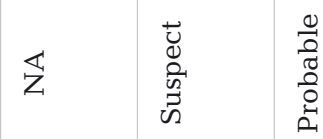

क्ष

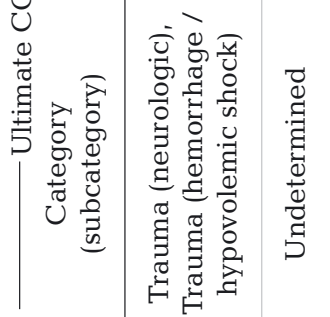

军 品

岂营

正

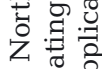

获:

Ð.

.

象

过 目

쥼

क्व

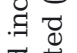

형후

जิ

눅굴

ฮั

पू

y

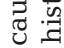

을

悬

을

$\stackrel{0}{0}$

胥

ค.

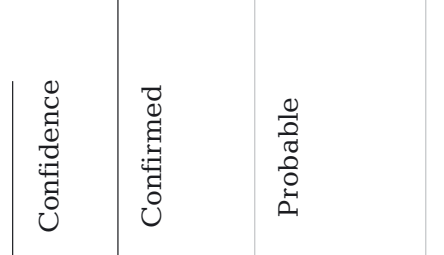

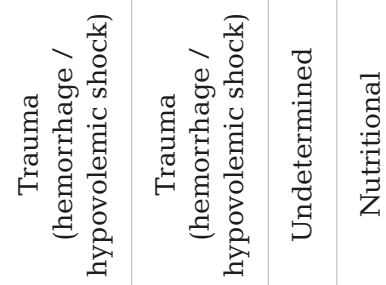

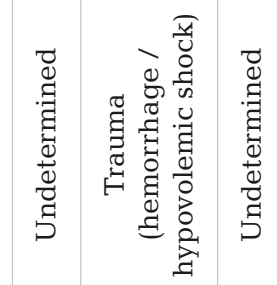

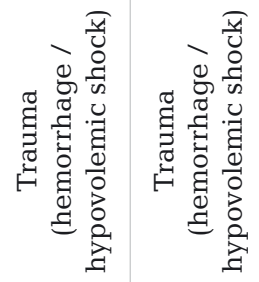

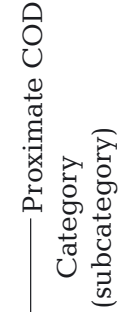

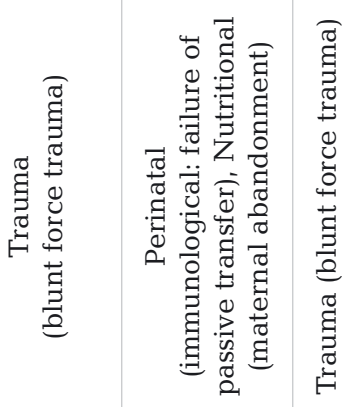

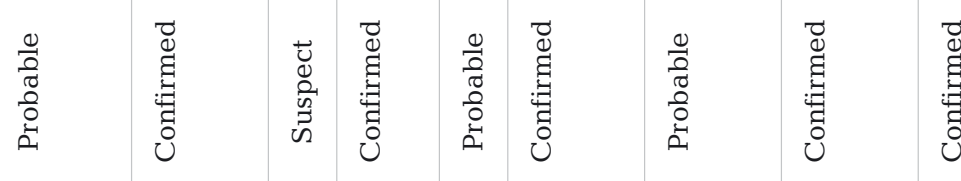

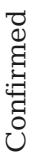

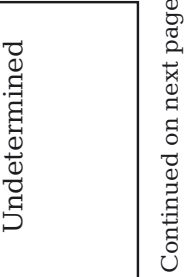

मे

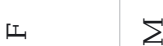

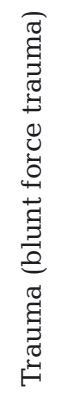

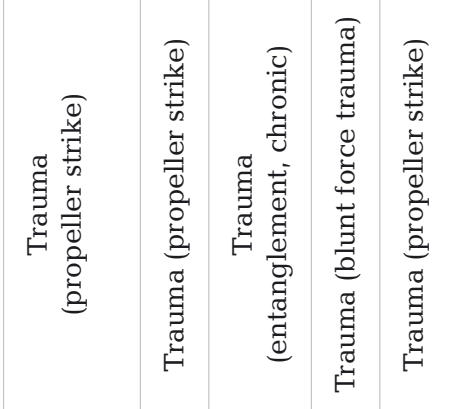

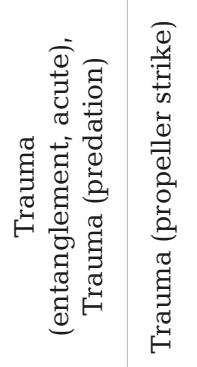

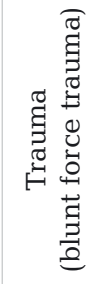

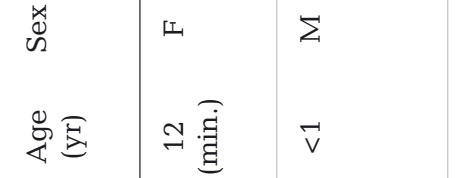

山 I

山曲

올

เ

는

山 $\Sigma$

山

山

山

ন

落

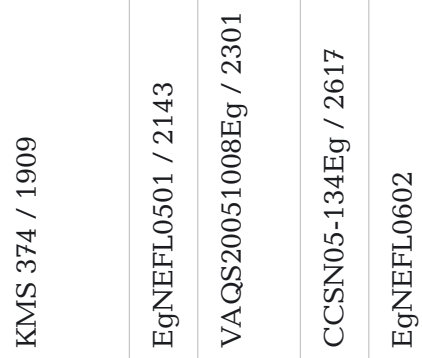

ô.

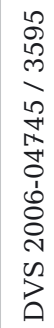

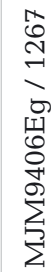

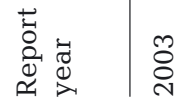

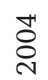

官

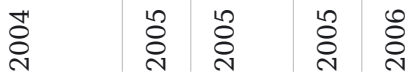

\&ัণ

\&્ণ

๕̊ 


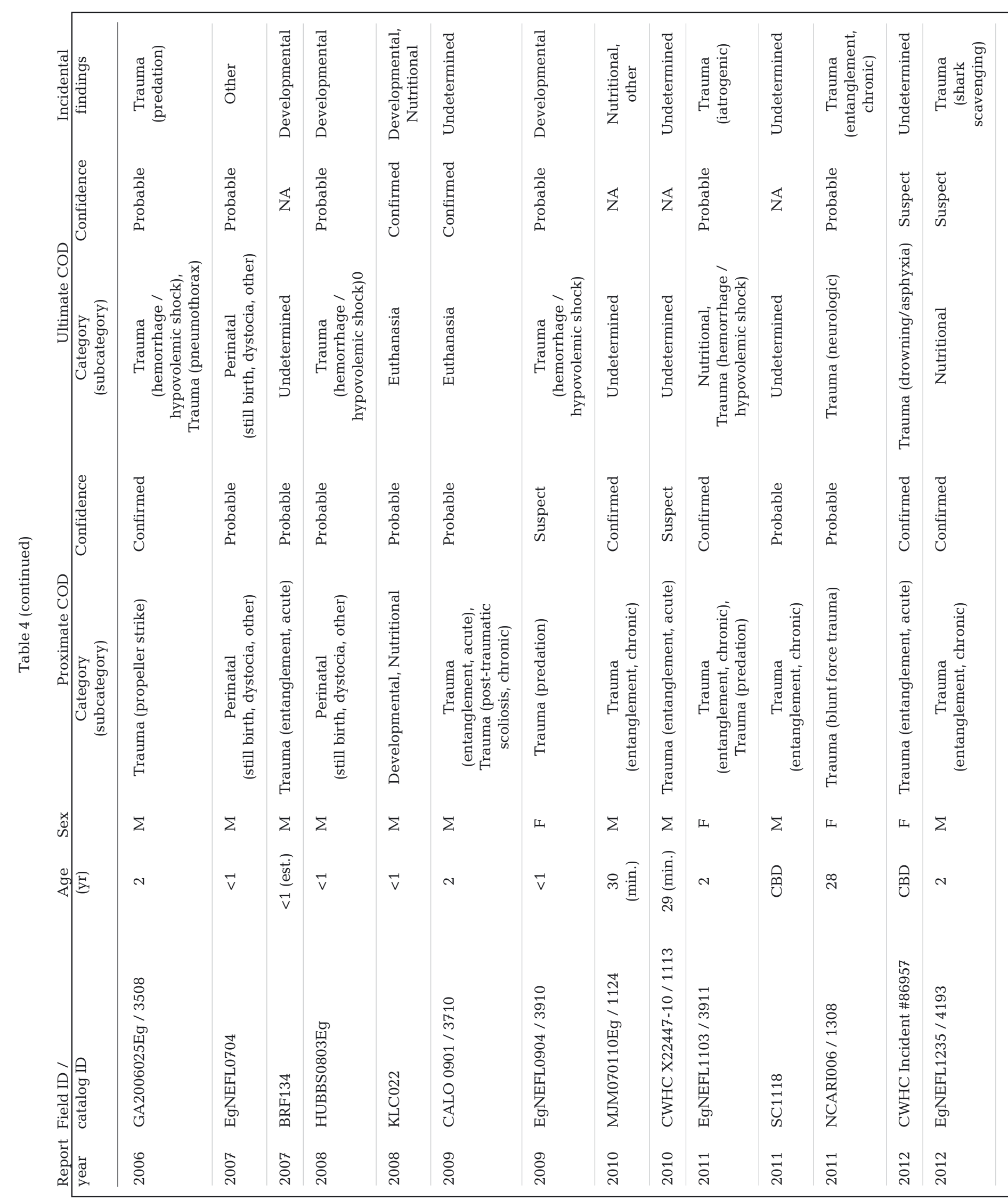

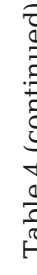




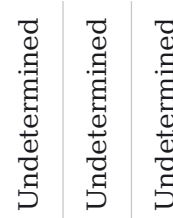

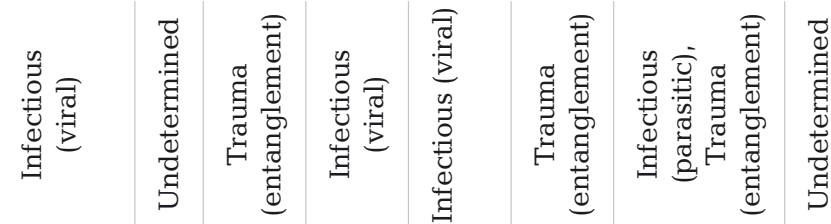

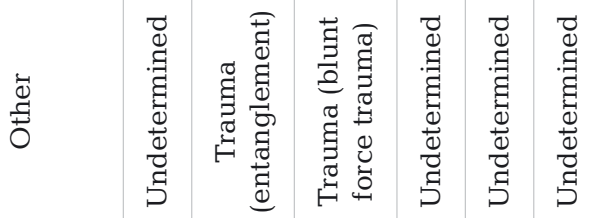

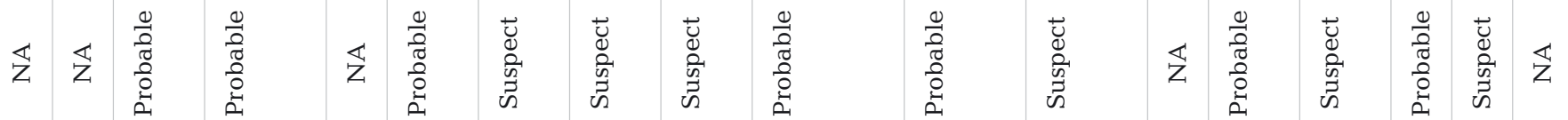
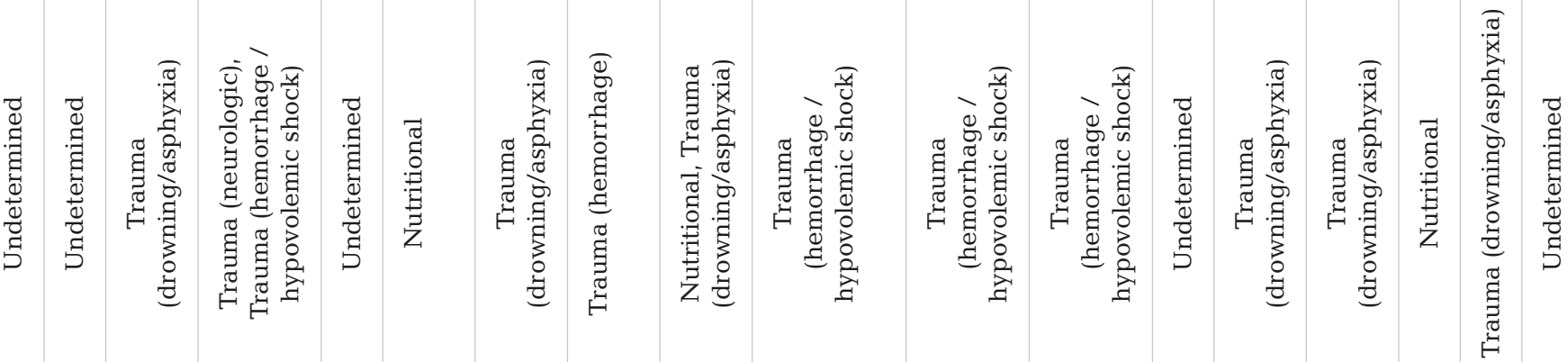

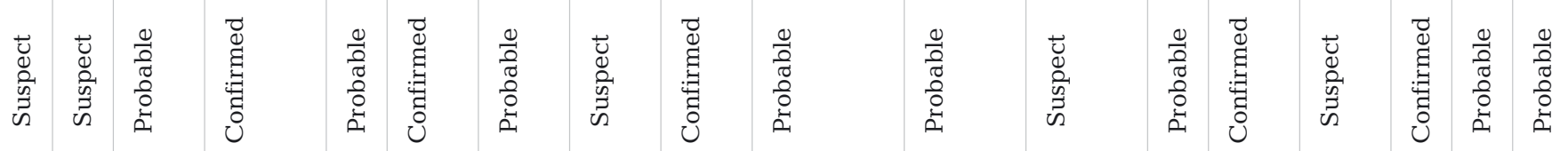

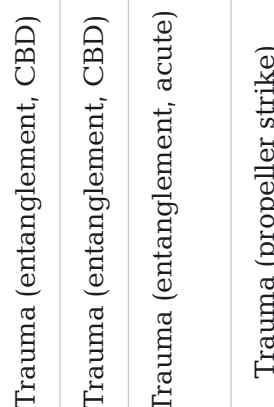

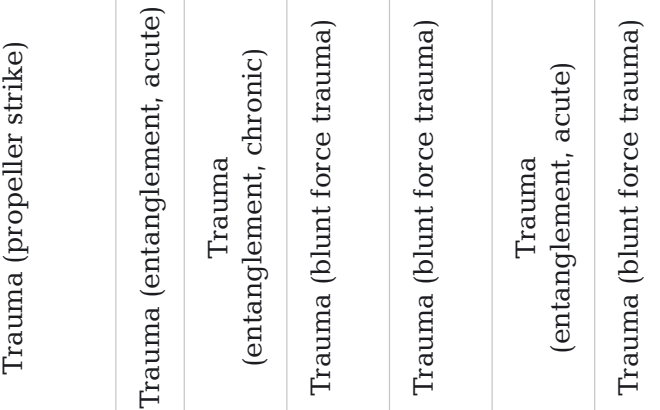

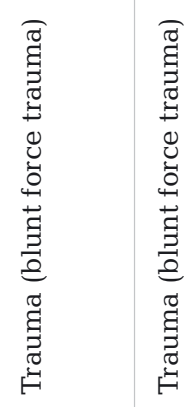

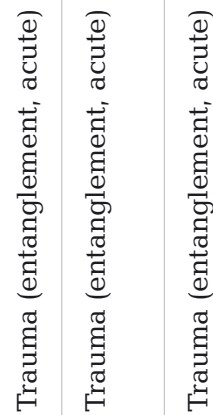

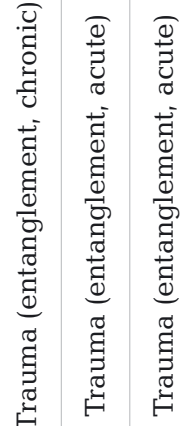

$\Sigma$ 苚

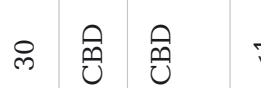

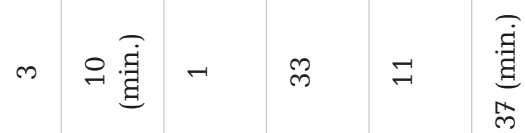

角

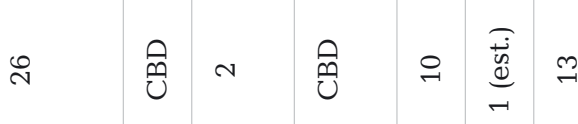

山 $\Sigma$ 山

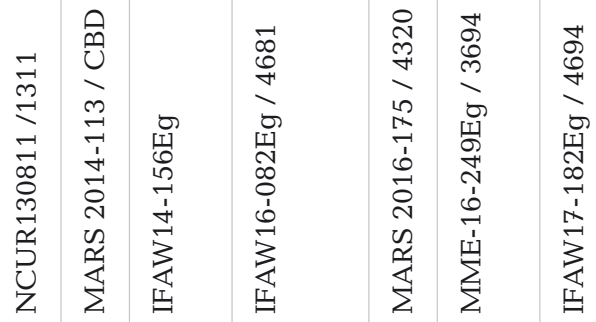

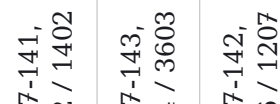

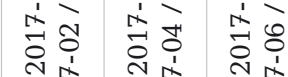

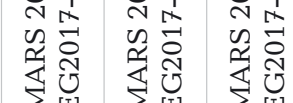

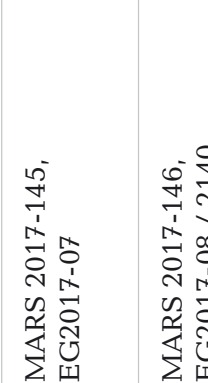

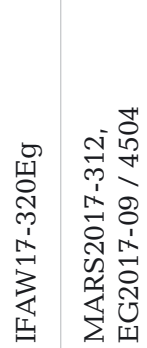

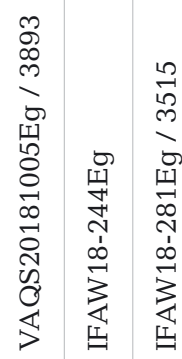

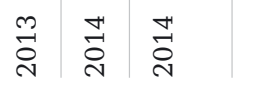

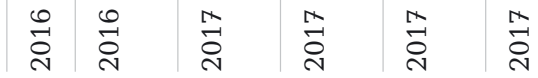

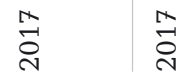

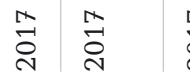

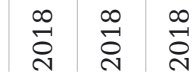


trauma) occurred in 7/16 (43.8\%) study years (20032006, 2011, 2016, and 2017; Fig. 2).

Of the 22 entanglement cases, $12(54.5 \%)$ were classified as acute (hours to days) and $7(31.8 \%$ ) as chronic (weeks to months) based on gross and histopathologic lesion characteristics (see Section 3.3.3 for details). Another case involved a suspected acute entanglement occurring when the whale was a calf with chronic complications that led to the animal's demise 1.5 yr later (CALO 0901). Two additional cases were examined only through photos and video from which it was not possible to determine entanglement chronicity. Of the NARWs that died from acute entanglement, $7 / 12(58.3 \%)$ were $3 \mathrm{yr}$ old or younger (or $<1000 \mathrm{~cm}$ total straight length) compared to only $2 / 8(25.0 \%)$ that died from chronic entanglement. Two cases that died due to entanglement trauma also showed evidence of perimortem shark predation that likely contributed to the animals' deaths (EgNEFL0603 / 3602, EgNEFL1103 / 3911, acute and chronic entanglement, respectively). Of the 8 whales with healed incidental scars from previous entanglements, 3 died due to a subsequent new entanglement and 5 to ship strikes. Confirmed NARW deaths attributed to entanglement occurred in $12 / 16(75.0 \%)$ study years $(2005-2007,2009-2014$, 2016-2018; Fig. 2).

Although not directly related to COD, 2 NARWs in this dataset (IFAW17-182Eg / 4694 and MARS2017141, EG2017-02 / 1402) were found to have multifocal ulcerations of the glossal mucosa, which were revealed to be erosions or ulcerations of the epithelium
(Fig. 3). No infectious agents were observed microscopically. Viral PCR in 1 case was negative for morbillivirus, calicivirus, and herpesvirus.

\subsection{Morphometrics}

Fig. 4 shows the logarithmic relationships between total straight length and minimum age for all NARW carcasses from 1970-2018 with measured lengths and known minimum ages (Fig. $4 \mathrm{a}_{i} \mathrm{R}^{2}=0.9239, \mathrm{p}<$ 0.001 ), and for only female NARWs that fit the same criteria (Fig. $4 b ; R^{2}=0.9488, p<0.0001$ ). Fig. 5 shows the relationships between weight and total straight length (Fig. 5a; exponential, $\mathrm{R}^{2}=0.9562, \mathrm{p}<0.0001$ ) and weight and minimum age (Fig. 5b; geometric, $\mathrm{R}^{2}=0.9680, \mathrm{p}<0.0001$ ) for NARW carcasses 19702018. Fig. 6 shows the geometric relationships between fluke width and total straight length (Fig. 6a; $\mathrm{R}^{2}=0.9078, p=0.0001$ ) and anterior flipper edge length and total length (Fig. $6 b_{;} R^{2}=0.9505, p<$ 0.0001) for all NARW carcasses from the same time period.

\subsection{Traumatic lesions}

Due to the large number of NARW mortality cases included in this study, individual case summaries and representative gross images are not included here but are reported in Supplement 2. Highlights of notable gross and histopathologic findings will be

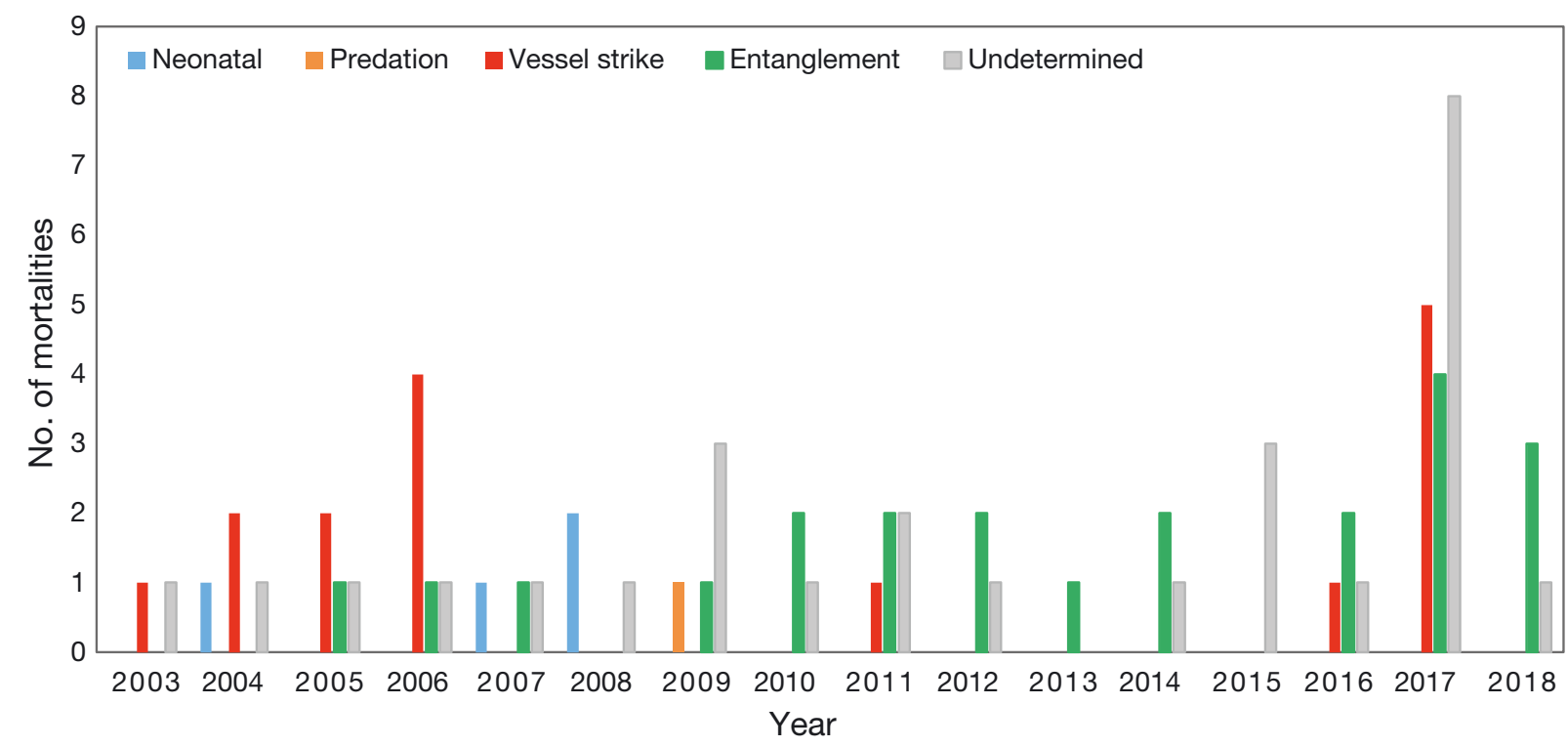

Fig. 2. North Atlantic right whale proximate causes of death by year 2003-2018. Proximate cause of death categories include neonatal mortalities, predation, entanglement, and unknown. A total of 70 mortalities occurred during the study period 

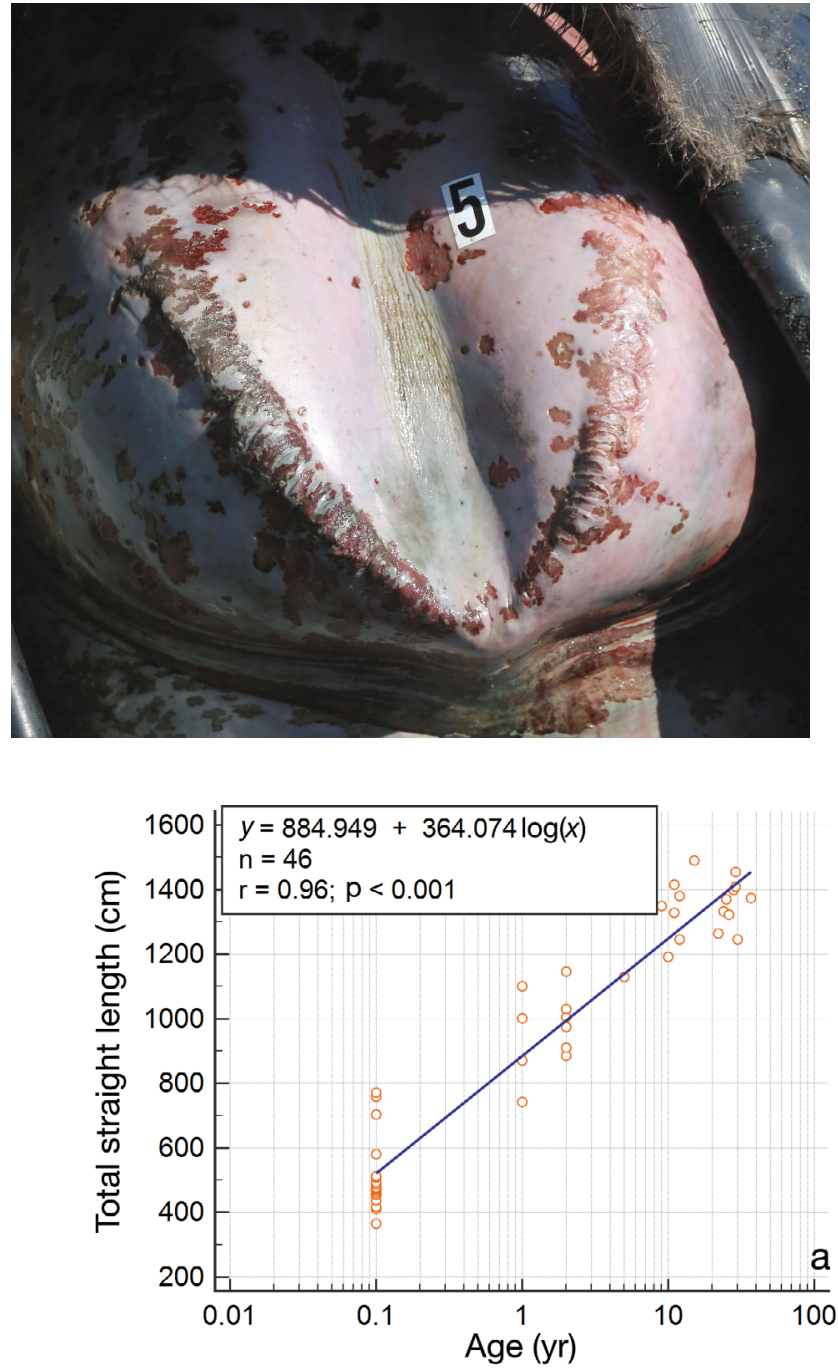

Fig. 3. North Atlantic right whale (IFAW17-182Eg / 4694; see Table 4) tongue; cause of death probable vessel strike blunt force trauma. Multifocal to coalescing glossal erosions and ulcerations were negative on PCR for herpesvirus, morbillivirus, and calicivirus. No infectious etiology was identified microscopically. Image credit: International Fund for Animal Welfare

presented here to emphasize frequently observed lesions, novel findings, and extent of trauma.

\subsubsection{Vessel strike - blunt trauma}

Of the NARWs that died due to vessel strike blunt trauma, bone fractures were a common finding, occurring in $8 / 10(80.0 \%)$ cases. Skull fractures occurred in 6 NARWs, 2 of which (MJM03-01Eg and NCAR1006Eg) had fractures that penetrated the

Fig. 4. Total straight length (actual or corrected) vs. age (minimum or actual) for North Atlantic right whale carcasses with measured (not estimated) lengths and known ages from 1970-2018 fitted with a logarithmic equation for (a) all whales $(\mathrm{n}=46)$ and (b) only female whales $(\mathrm{n}=24)$
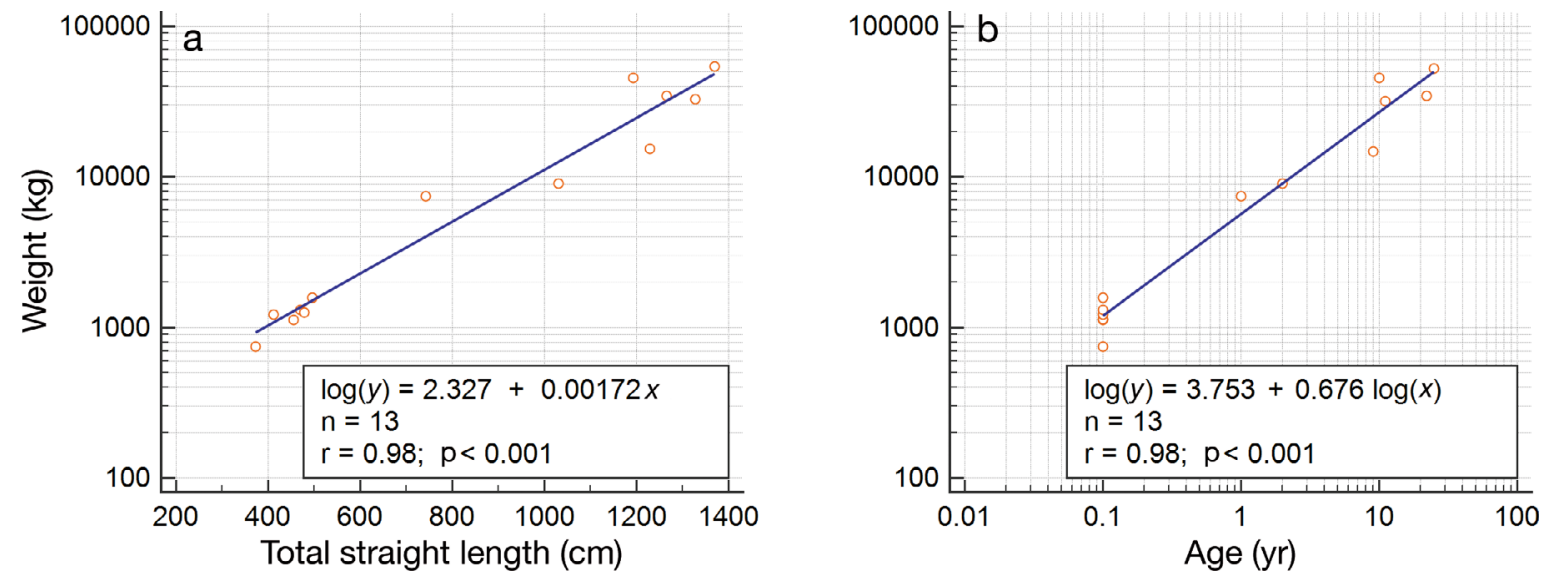

Fig. 5. (a) Weight (actual or corrected) vs. total straight length (actual or corrected) for all North Atlantic right whale carcasses with available data 1970-2018 ( $\mathrm{n}=13$ ) fitted with an exponential equation. (b) Weight (actual or corrected) vs. age (minimum or actual) for all whales with available data from 1970-2018 $(\mathrm{n}=14)$ fitted with a geometric equation 

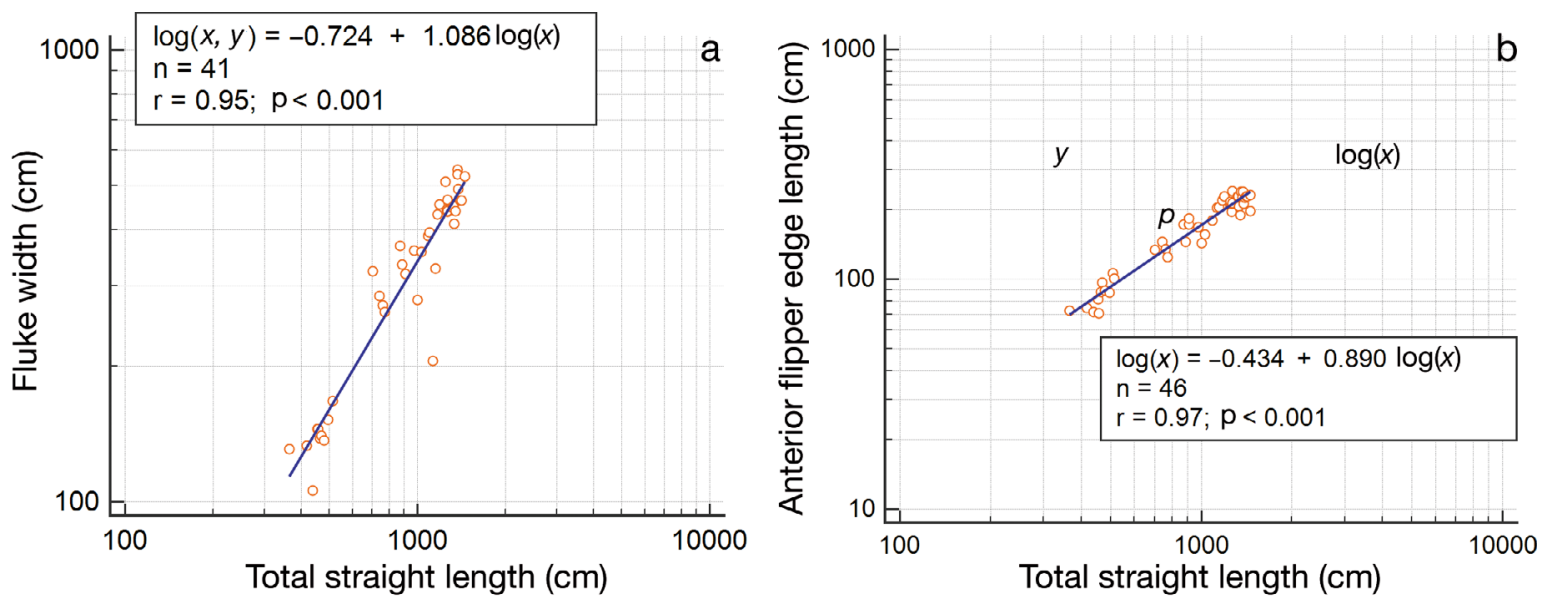

Fig. 6. (a) Fluke width (actual) vs. total straight length (actual or corrected) for all North Atlantic right whale carcasses with available data from 1970-2018 ( $\mathrm{n}=41$ ) fitted with a geometric equation. (b) Anterior flipper edge length (actual) vs. total straight length (actual or corrected) for all whales with available data from 1970-2018 $(n=46)$ fitted with a geometric equation

neurocranium (brain case), likely resulting in nearly immediate death from catastrophic central nervous system injury (Fig. 7a). In 3 cases, the oral vascular retia (corpus cavernosum maxillaris; see Ford et al. 2013) were lacerated from the trauma, likely leading to fatal hemorrhage and hypovolemic shock (MARS 2017-145/EG2017-07, MJM03-01Eg / 2150, VMSM 20041004 / 1004). Fractured petrotympanic complexes (ear bones; Fig. 7b) were also common, although sometimes they were attributed to postmortem causes when other supportive evidence of blunt trauma was not present. Vertebral fractures occurred in 3 cases, with transverse and/or spinous process fractures in all cases (Fig. 8a), and vertebral centrum (body) fractures in 2 cases (Fig. 8b). Vertebral process fractures were often present in multiple contiguous vertebrae and were associated with black putty-like material consistent with antemortem blood that had coagulated and lysed due to postmortem heat and pressure (Fig. 8). Large perimortem blood clots were present in 9/10 (90\%) blunt trauma cases in various locations including along fracture sites (as just mentioned), adjacent to intact vertebrae, and

Fig. 7. (a) North Atlantic right whale (MJM03-01Eg / 2150; see Table 4); cause of death: confirmed vessel strike blunt trauma. Large basilar skull fracture just to the left of the occipital condyles (knife is shown entering the foramen magnum at the arrow and visible through the fracture). Skull is inverted in image. (b) MARS 2017-145, EG2017-07; cause of death: probable vessel strike blunt trauma. Petrotympanic complexes (ear bones) fractured at their base. Image credits: (a) Woods Hole Oceanographic Institution; (b) Gilbert Boyer (Canadian Wildlife Health Cooperative)
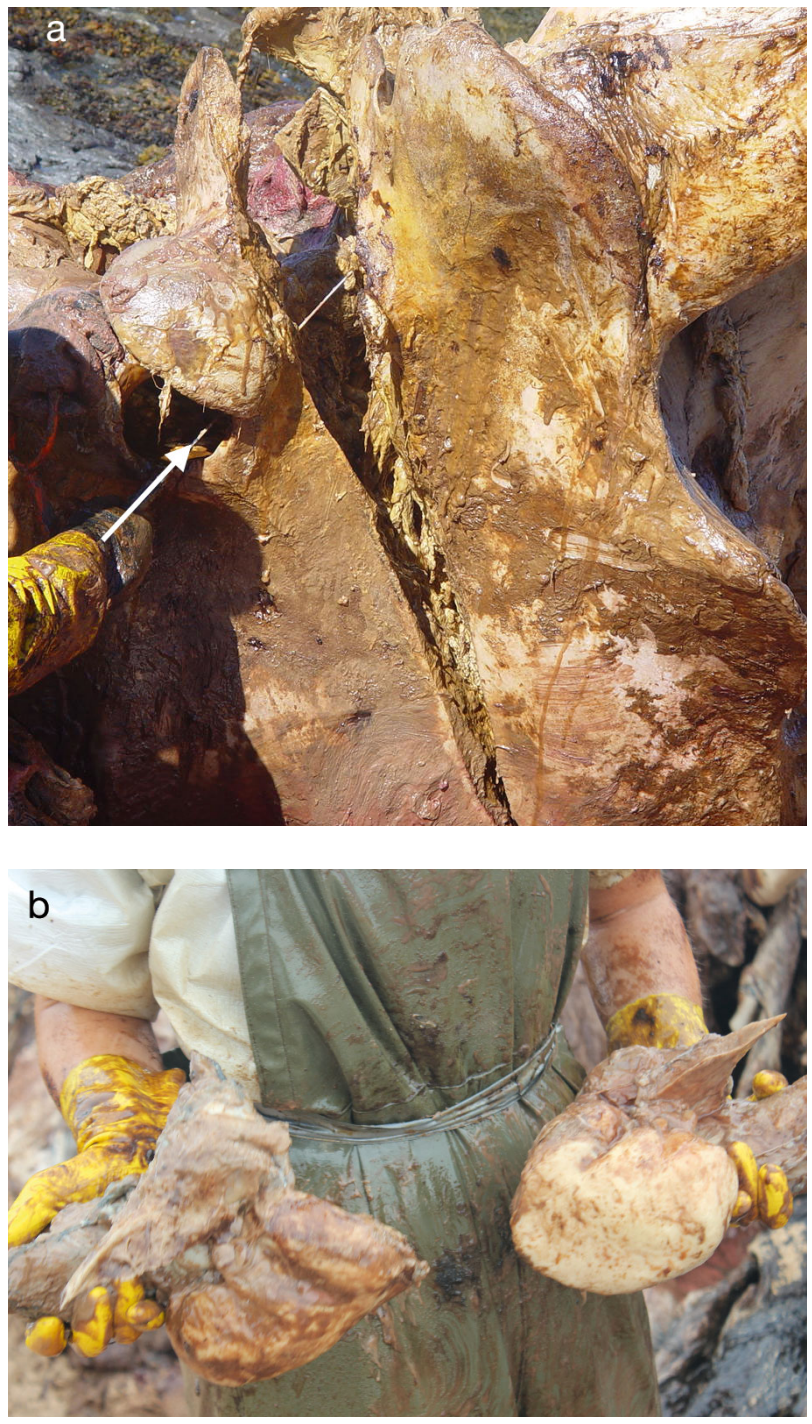

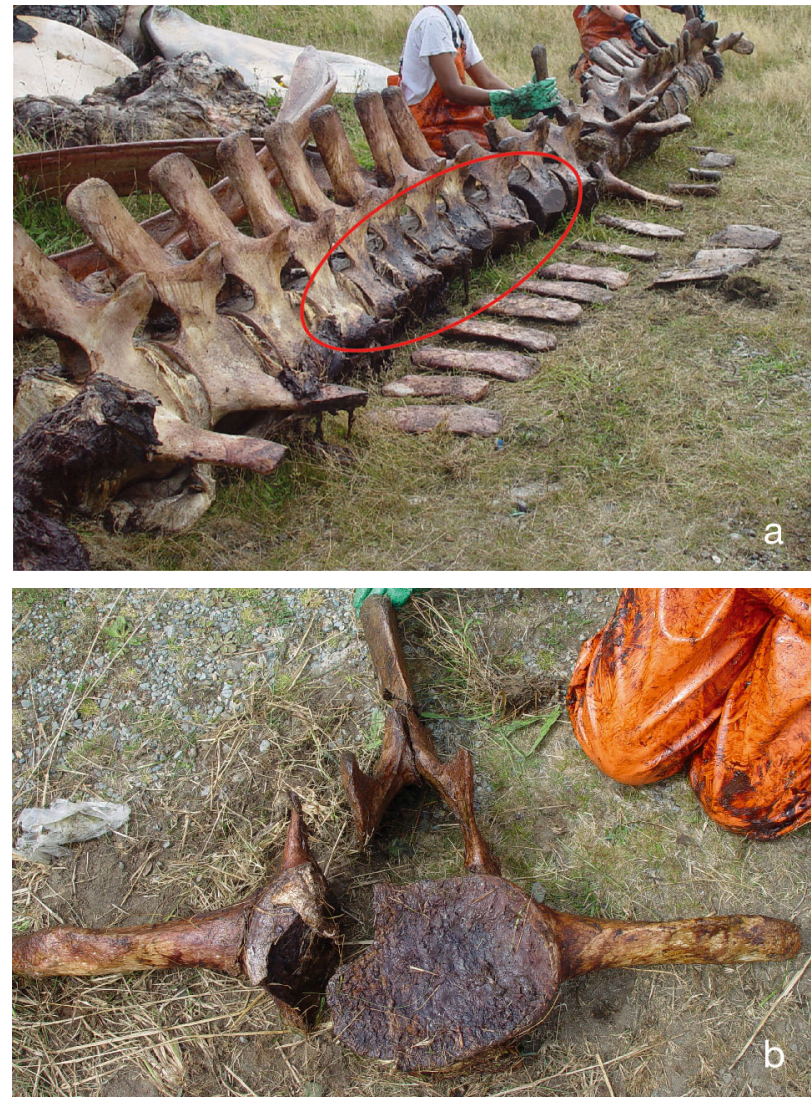

Fig. 8. North Atlantic right whale (MJM9406Eg / 1267; see Table 4); cause of death: confirmed vessel strike blunt force trauma. (a) Vertebrae displaying multiple contiguous fractured transverse processes. Note the black, putty-like substance surrounding the fracture sites (oval), consistent with clotted blood from hemorrhage. (b) Fractured vertebral centrum with fractures of the spinous process and vertebral arch. Image credits: Woods Hole Oceanographic Institution

free within body cavities (Fig. 9). These clots presented as dark brown to black putty-like substance with no obvious cells or structure microscopically.

Another common gross finding in vessel strike blunt trauma cases was a well-demarcated region of muscle and overlying blubber contusion. The texture of contused muscle was more gelatinous (presumptive perimortem edema and hemorrhage from ruptured capillaries) and the color was darker compared to adjacent muscle (Fig. 10). Blubber contusions were often superficial to the muscle contusions and included patchy to undulating regions of hemorrhage in some cases (Figs. 10-12). In order to be considered significant and rule out lividity, these changes were restricted to a well-delineated region and not diffusely distributed on the dependent surface of the animal (keeping in mind that the depend-

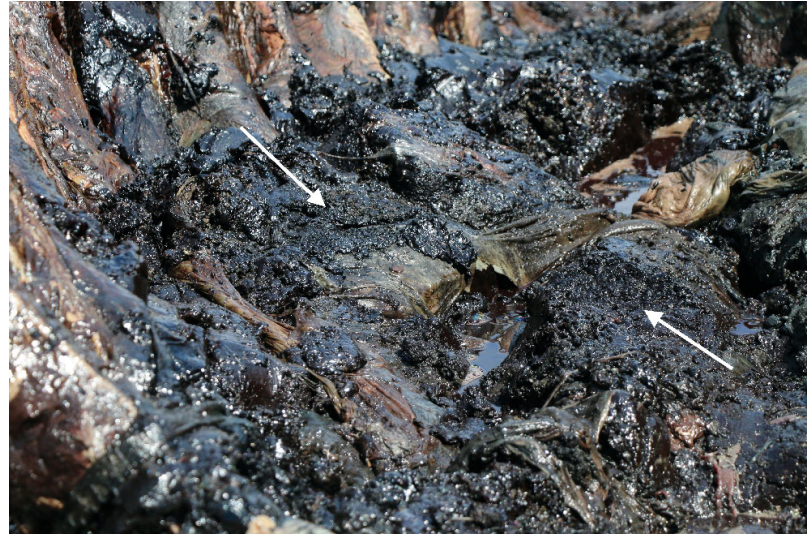

Fig. 9. North Atlantic right whale (MARS 2017-142, EG201706 / 1207; see Table 4); cause of death: probable blunt force trauma vessel strike. Abundant black putty-like material (arrows), consistent with clotted blood, was present in the thoracic cavity. Image credit: Marine Animal Response Society/Canadian Wildlife Health Cooperative

ent surface may have changed over time between floating at sea, stranding, and necropsy). Histopathologic lesions in vessel strike blunt trauma cases included erosion, ulceration, edema, congestion, and hemorrhage in the blubber and skin. Myofiber degeneration with fibrin exudation and erythrocyte extravasation were also observed. However, in many blunt trauma cases, the state of decomposition was advanced, making gross findings more instrumental in establishing the COD than histopathologic lesions.

\subsubsection{Vessel strike - propeller-induced trauma}

All 6 propeller-struck whales suffered deep lacerations (Semeraro et al. 2012), evidenced by torn and crushed soft tissue in a curvilinear, S- or Z-shaped pattern (indicating a left-handed or right-handed propeller, respectively) (Rommel et al. 2007), often (but not always) having multiple parallel wounds. The depth and number of wounds varied among cases. GA2006025Eg / 3508 sustained at least 20 relatively short lacerations and chop wounds, some deep into muscle and the thoracic cavity, the latter of which caused a fatal pneumothorax (Fig. 13). IFAW16-082Eg / 4681 sustained fewer longer lacerations and chop wounds, one of which penetrated deep into the abdominal cavity likely lacerating viscera (Fig. 14). Three propeller trauma cases also had associated skull fractures (KMS 374 / 1909, GA2006025Eg / 3508, IFAW16-082Eg / 4681), 1 had vertebral shearing and fractures (IFAW16-082Eg / 4681), and 1 calf had a complete peduncle and fluke amputation (Eg- 

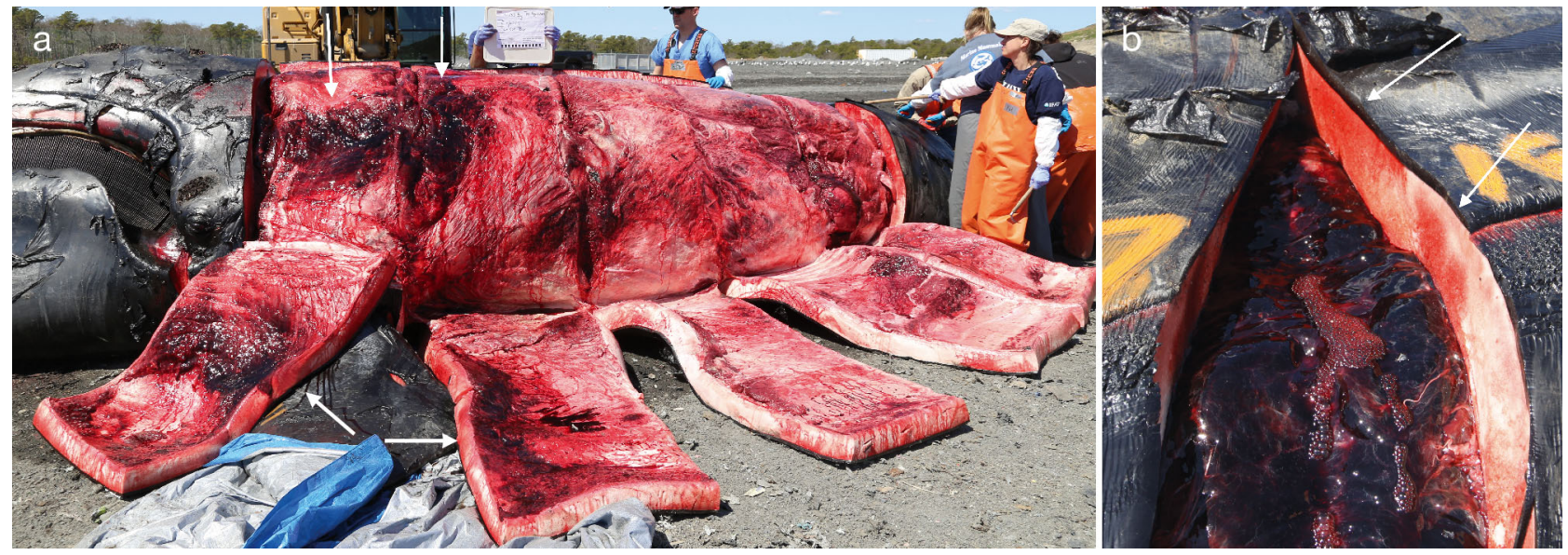

Fig. 10. North Atlantic right whale (IFAW17-182Eg / 4694; see Table 4); cause of death: probable vessel strike blunt trauma. (a) Left lateral body with reflected blubber showing a focal patchy blubber contusion (lower arrows) overlying a focal muscular contusion/hematoma (upper arrows). (b) Close-up showing blubber contusion (arrows) and underlying gelatinous (contused) muscle. Image credits: International Fund for Animal Welfare
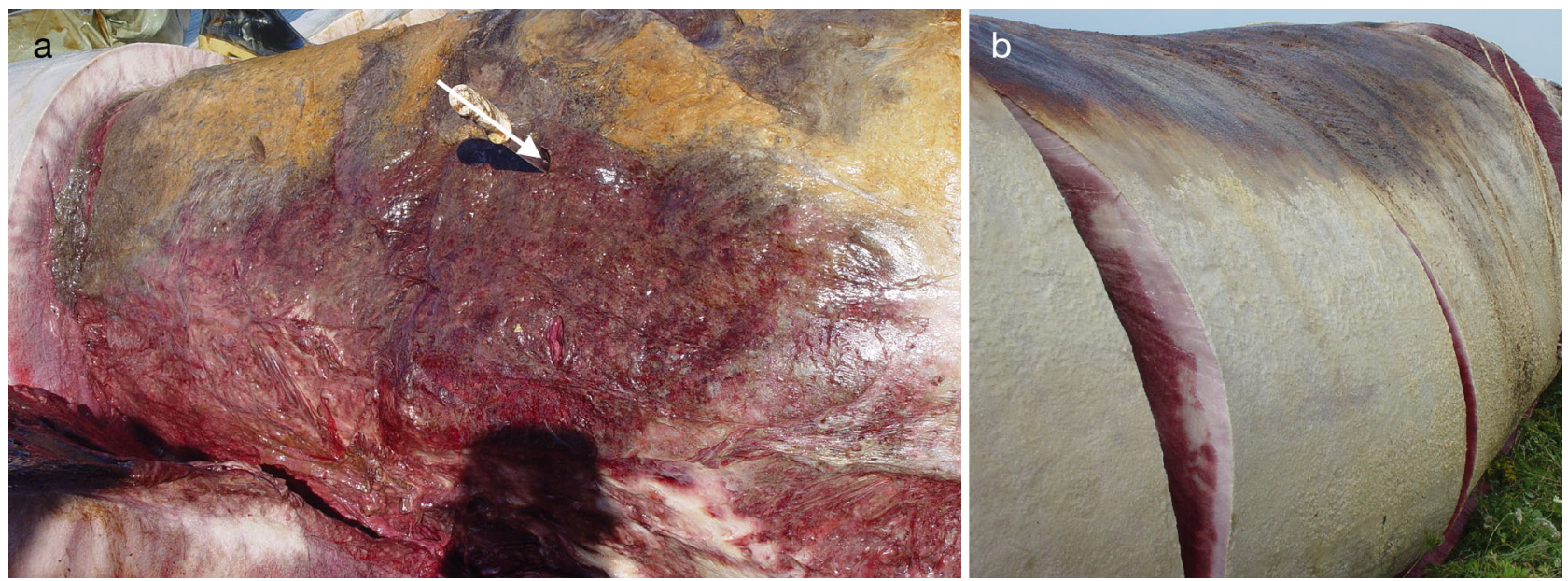

Fig. 11. (a) North Atlantic right whale (MJM03-01Eg / 2150; see Table 4); cause of death: confirmed blunt trauma vessel strike. Muscle contusion superficial to a mandibular fracture. Knife (arrow) probes the fracture site. Reflected contused blubber can also be seen overlying the muscle contusion. (b) MJM9406 / 1267; cause of death: confirmed blunt trauma vessel strike. Undulating pattern of hemorrhage in blubber (foreground) on the left lateral abdomen just cranial to genital aperture. Image credits: Woods Hole Oceanographic Institution

NEFL0602, Fig. 15). In 1 of the 6 propeller trauma cases (KMS 374 / 1909), a Navy vessel reported striking a live NARW and observed the whale immediately after the collision, bleeding and missing a fluke blade; the carcass was found 1 wk later (Fig. 16). Another vessel strike case (NEFL0501Eg / 2143) involved a whale with healed scars from a propeller interaction that occurred $14 \mathrm{yr}$ earlier when she was a calf (Fig. 17). This individual subsequently became pregnant and died with a full-term fetus in utero. Based on gross and histopathologic findings, increased intraabdominal pressure caused by the increased volume of the developing fetus exceeded the reduced tensile strength of the propeller scars, leading to splitting of the deposited collagen, subsequent entry of bacteria into the open scar, abscess formation, and presumed sepsis. In propeller trauma cases, the ultimate causes of death were most often hypovolemic and/or neurogenic shock from hemorrhage and/or central nervous system trauma, respectively. Associated histopathologic lesions included hemorrhage and edema in blubber, muscle, and bone. Myofiber degeneration characterized by sarcoplasmic clumping and granularity with loss of cross-striations (myofiber disruption) was occasionally observed. However, the wash-out effect observed in floating carcasses may affect the ability to detect acute hemorrhage, edema, and inflammation at the site of injury (i.e. cellular evidence is washed 


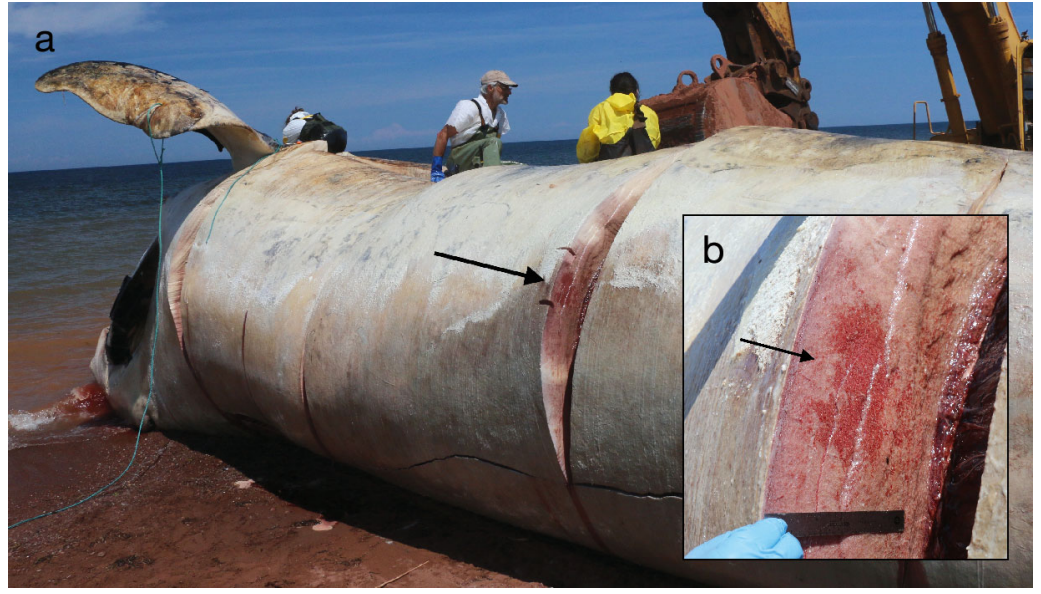

Fig. 12. (a) North Atlantic right whale (MARS 2017-142, EG2017-06 / 1207; see Table 4); cause of death: probable blunt force trauma vessel strike. Distinct region of focal blubber contusion in right lateral body wall. (b) Close-up of region shown in (a). The arrow in each photo points to the same area. Image credit: Marine Animal Response Society away by the aquatic environment prior to sampling).

\subsubsection{Entanglement}

Notable gross soft tissue entanglement lesions included lacerations caused by constrictive wraps of line primarily around the axilla/flippers, flukes/peduncle, and the head/mouth. In acute cases, corresponding histopathologic lesions included superficial compression, epidermal erosion and ulceration, dermal and hypodermal edema and hemorrhage, and little to no evidence of inflammation or fibrosis. Chronic soft tissue entanglement lesions had evidence of fibrosis
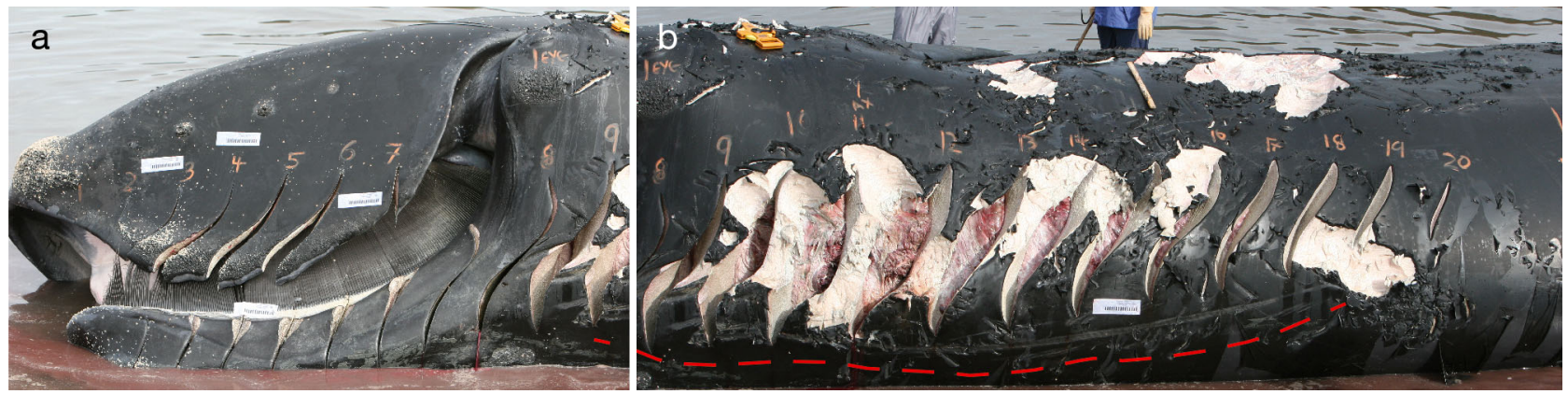

Fig. 13. North Atlantic right whale (GA2006025 / 3508; see Table 4); cause of death: confirmed vessel strike propeller trauma. Right lateral head and body showing 20 Z-shaped penetrating chop wounds (numbered 1-20) consistent with a right-handed propeller interaction. A linear non-penetrating abrasion coursing parallel to the wound axis is also visible dorsal to the propeller wounds (above and parallel to dashed line) suggestive of a skeg or rudder interaction. Image credit: Florida Fish and Wildlife Conservation Commission
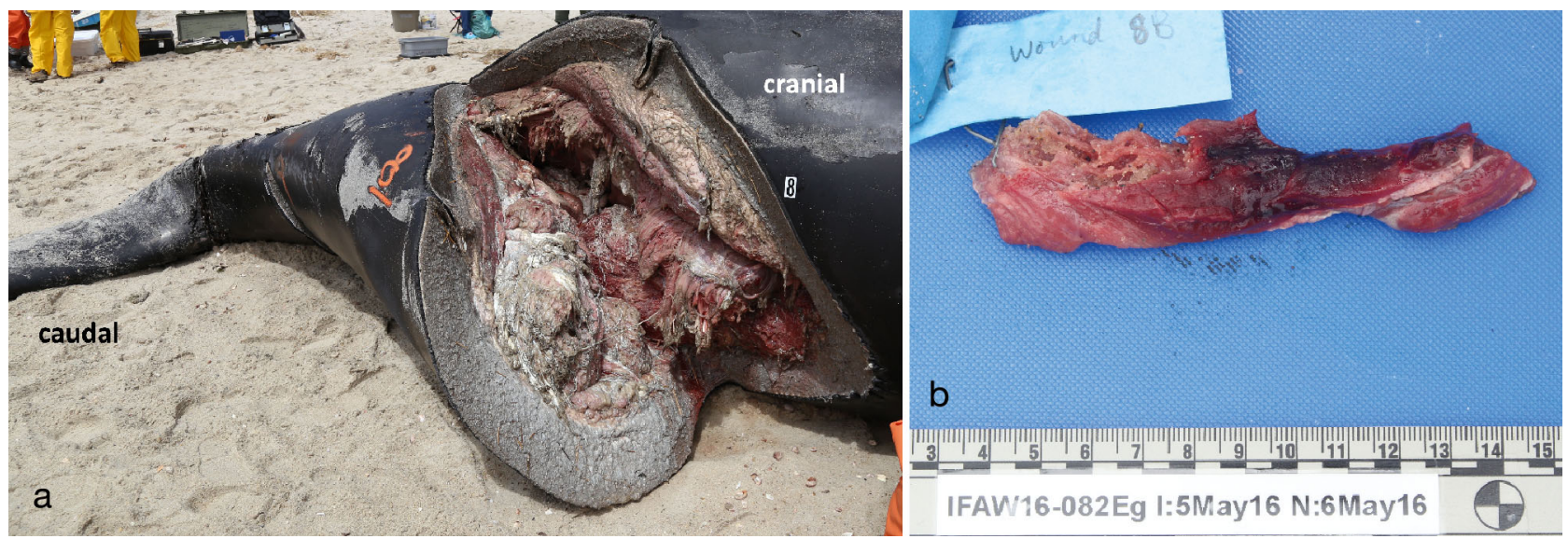

Fig. 14. North Atlantic right whale (IFAW16-082Eg / 4681; see Table 4); cause of death: confirmed propeller strike. (a) Deep transecting oblique chop wound on the caudal left ventrolateral body consistent with a left-handed propeller interaction, extended deep through blubber and muscle and into the abdominal cavity. Numerous lumbar and caudal vertebrae were also fractured and shorn by the impact. (b) Lesion hemorrhage and washout as observed at necropsy. Image credits: International 


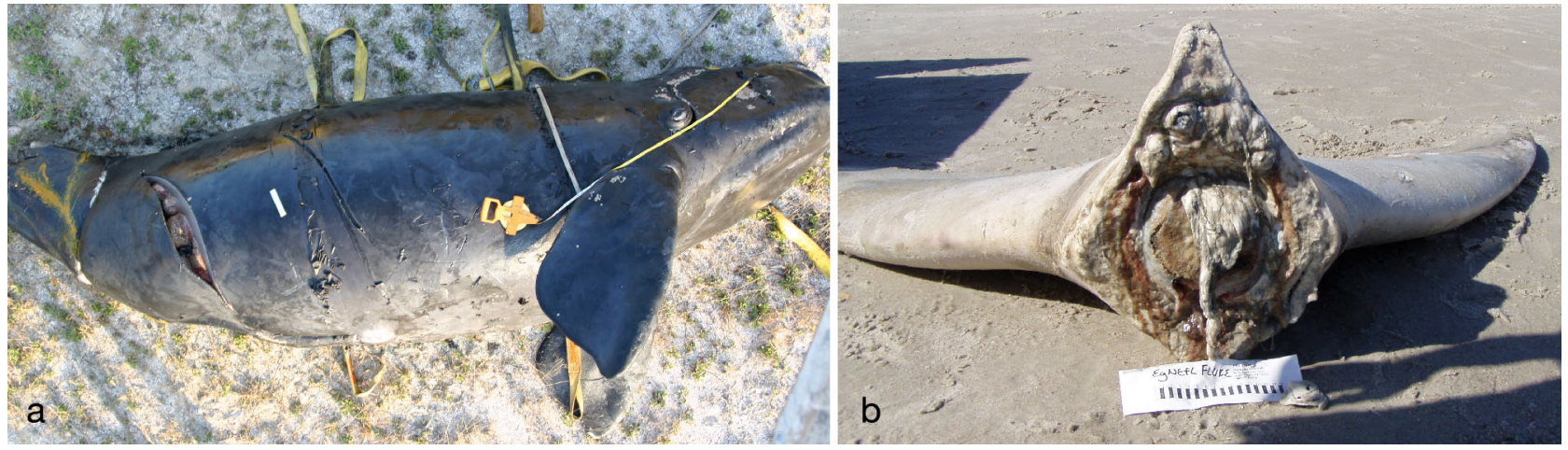

Fig. 15. North Atlantic right whale calf (EgNEFL0602; see Table 4); cause of death: confirmed vessel strike, propeller trauma. (a) Right lateral body with S-shaped lacerations consistent with left-handed propeller strike. (b) Caudal peduncle and flukes from the same whale that were severed by the propeller and later washed ashore. Image credits: Florida Fish and Wildlife Conservation Commission
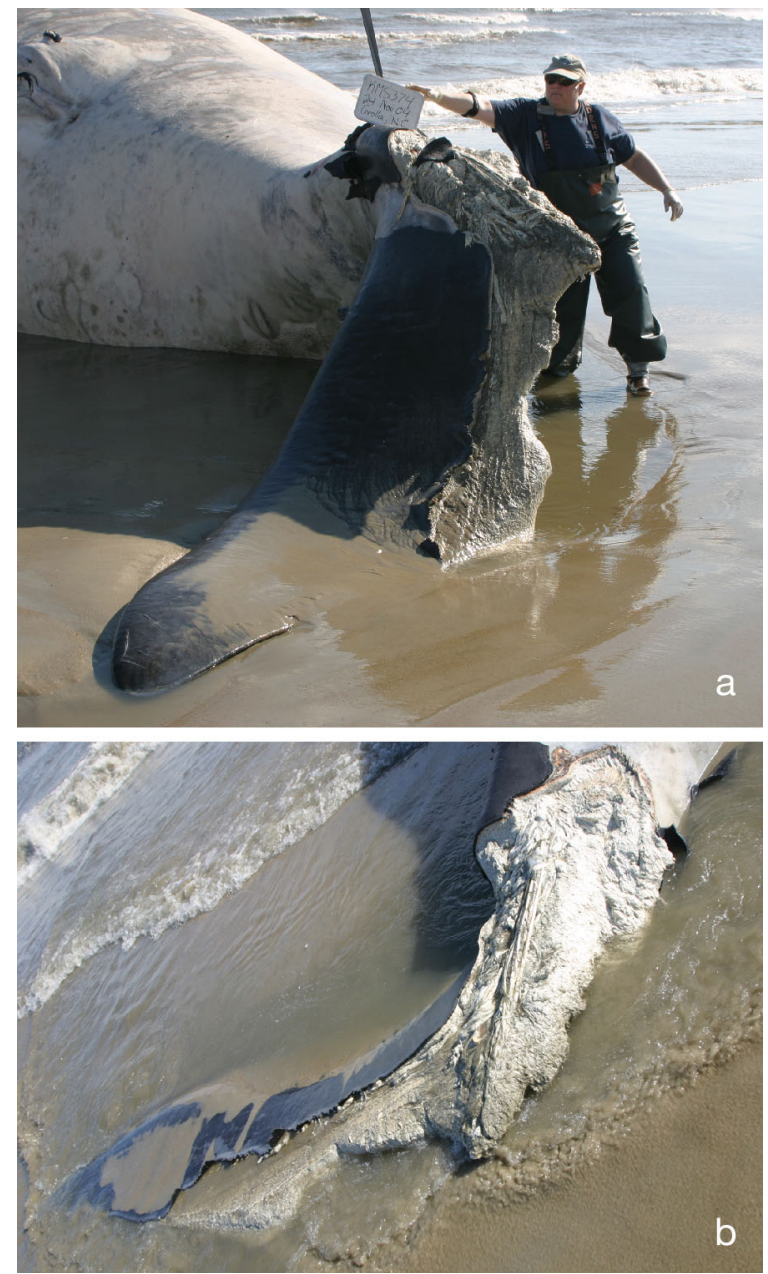

Fig. 16. North Atlantic right whale (KMS 374 / 1909; see Table 4); cause of death: confirmed propeller strike. (a) Right fluke blade severed by propeller, tearing large vessels and severing the terminal 3-4 caudal vertebrae. (b) Close-up of the injury. Image credits: Virginia Aquarium \& Marine Science Center / University of North Carolina at Wilmington in the epidermis, dermis, and hypodermis, with myofiber atrophy in some flipper entanglements. Inflammation was notably absent in chronic lesions as well, perhaps due to decreased vascularity in these regions. In some cases, chronically entangling line was deeply embedded within an envelope of soft tissue fibrosis and scarring (Fig. 18b). Of the 7 whales with evidence of chronic entanglement (1 died due to vessel strike blunt trauma, see Table 4), all exhibited osteopathic lesions due to chronically impinging line including periosteal proliferation $(\mathrm{n}=6$, Figs. 19 \& 20 ), osteopenia ( $n=3$, Fig. 21), and lytic lesions ( $\mathrm{n}=$ 2, Figs. 20c \& 22b). Periosteal proliferation was often exuberant in response to the repetitive injury caused by the line (Figs. $19 \& 20$ ). Despite the avid new bone growth in many of these cases, the line passively (and likely slowly) inflicted a partial amputation of the affected flipper (Figs. $19 \& 20$ ). Another case (CALO 0901) previously documented as a live calf with scars from a (presumed acute) peduncle/fluke entanglement, live-stranded $>1$ yr later with entanglement-induced osteolysis, sclerotic and proliferative changes in the caudal vertebrae, unilateral dystrophic mineralization of the surrounding soft tissues, and resultant traumatic scoliosis (Fig. 22). A different case with an extensive and chronic fluke entanglement had osseous metaplasia of the peduncle soft tissue (EgNEFL1235 / 4193). In many chronically entangled whales, poor body condition and widespread epidermal cyamid ('whale louse') infestations were present (Fig. 18a), indicating overall compromised health.

Baleen plate separation and/or mutilation due to entangling line was observed in 5 cases (VAQS20051008Eg, EgNEFL1103, MME16-249Eg, MARS2017312/EG2017-09, VAQS2018-1005Eg; Fig. 23a), in- 

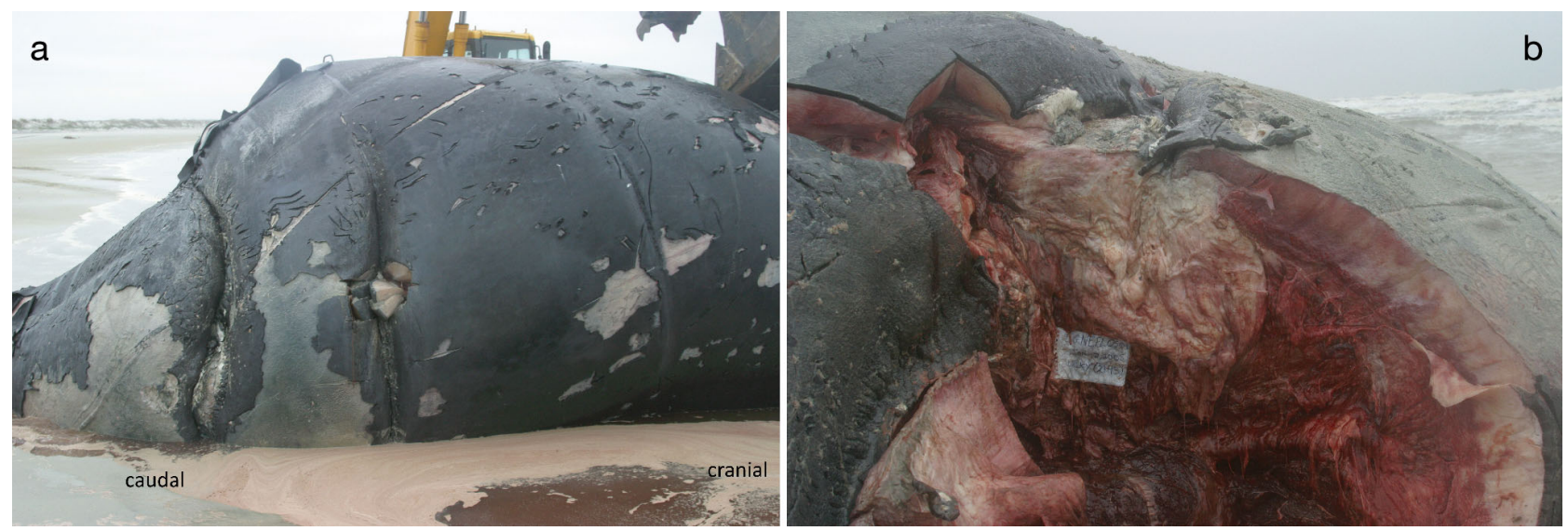

Fig. 17. North Atlantic right whale (EgNEFL0501 / 2143; see Table 4) showing (a) old propeller wounds at time of necropsy. (b) Dissection of caudal-most wound in (a) showing abscessed granular tissue and necrosis associated with the old propeller wound. Image credits: University of North Carolina at Wilmington
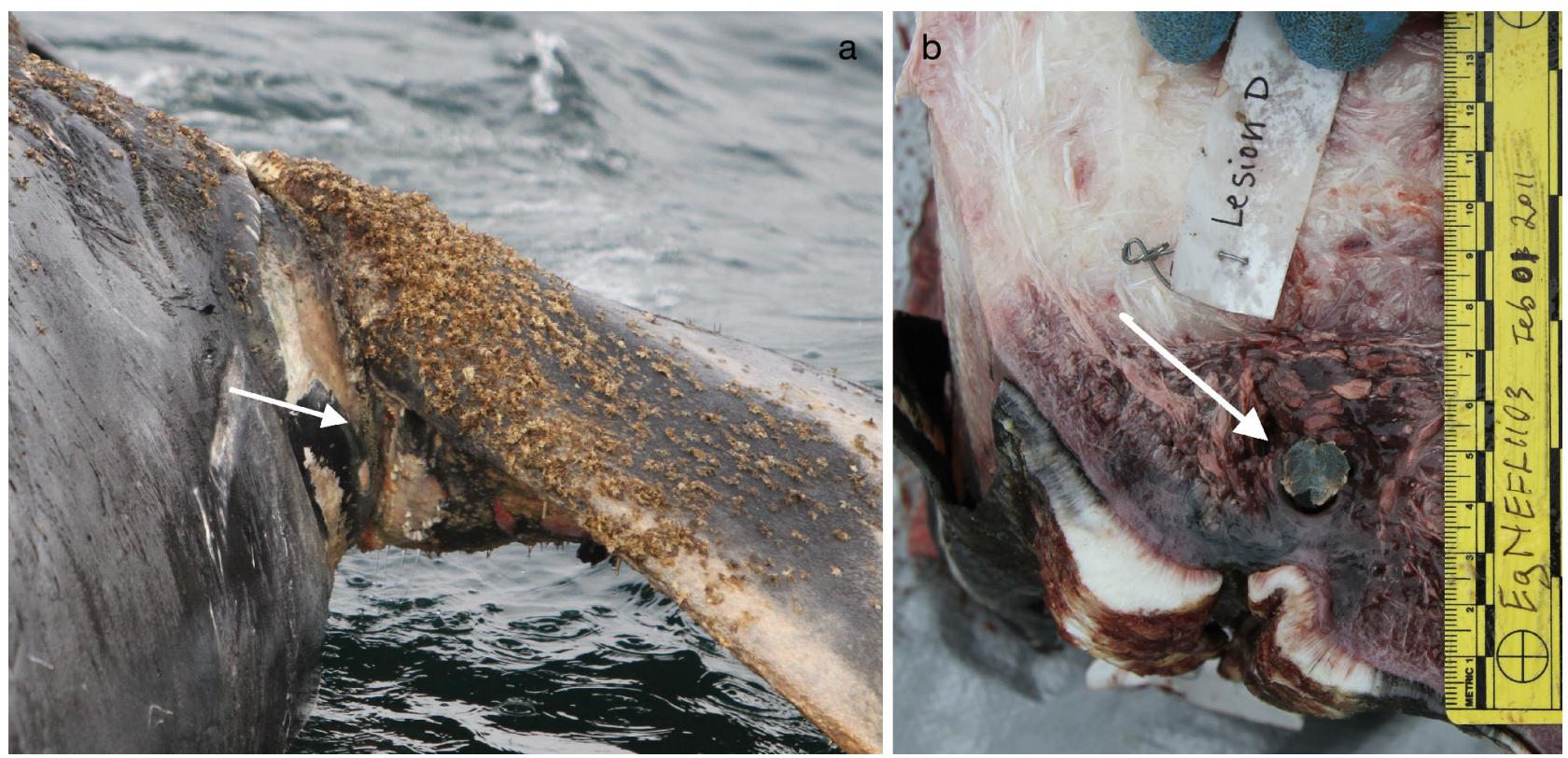

Fig. 18. North Atlantic right whale (EgNEFL1103 / 3911; see Table 4); cause of death: confirmed chronic entanglement. (a) View of right axilla from the caudal perspective showing extensive orange cyamid coverage on the affected flipper. The embedded entangling line can be seen at the arrow. (b) Right lateral lip in cross-section showing embedded line (arrow) and surrounding hemorrhagic edema. Image credits: Florida Fish and Wildlife Conservation Commission
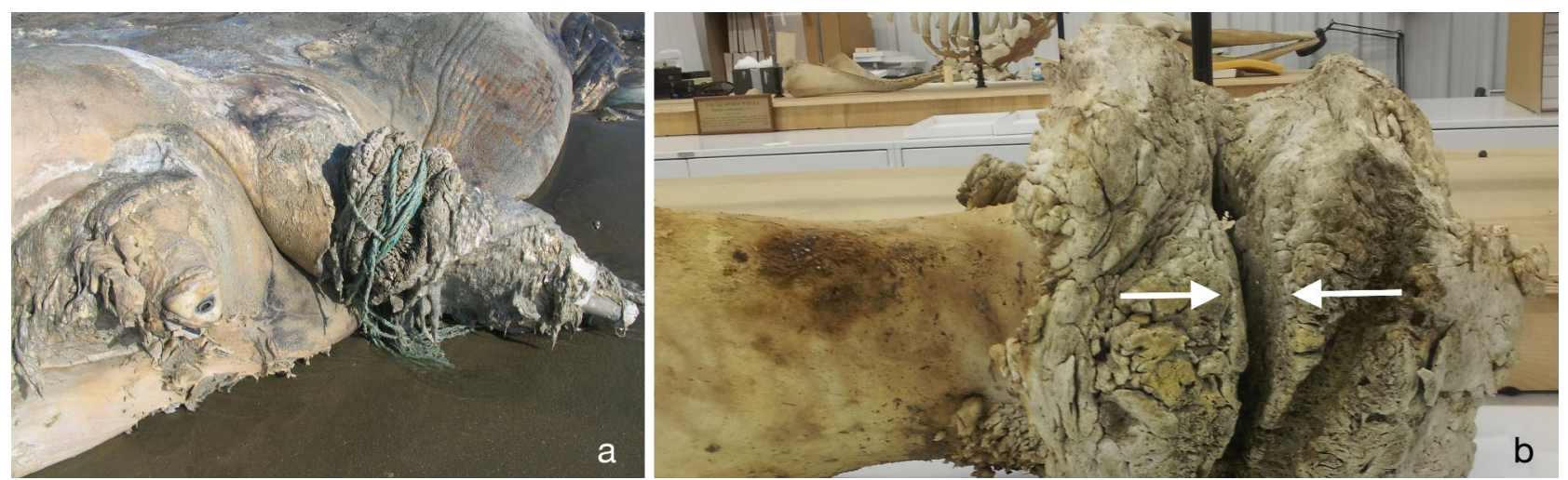

Fig. 19. North Atlantic right whale (SC1118; see Table 4); cause of death: probable chronic entanglement (entanglement confirmed, role in death is probable). (a) 13 wraps of entangling line were found around the right pectoral flipper. (b) Flensed humerus showing exuberant proliferative periosteal reaction (new bone formation) near the humeral head and a furrow caused by the chronically impinging line (arrows). Image credits: NOAA National Ocean Service Center for Coastal Environmental Health and Biomolecular Research Coastal Marine Mammal Strandings and Assessments Project 

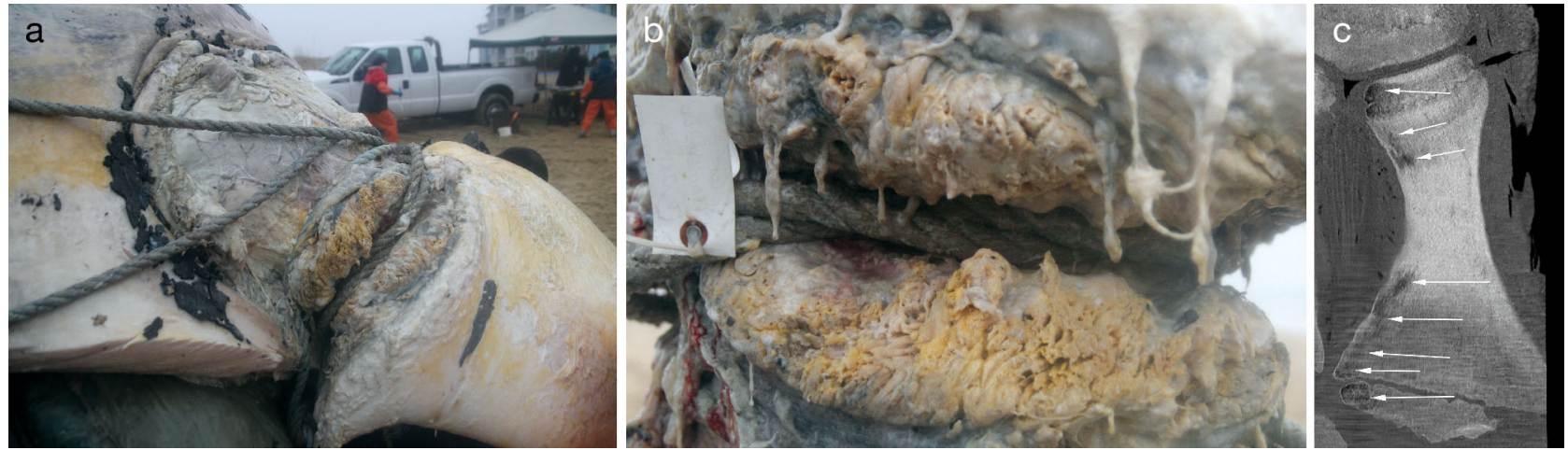

Fig. 20. North Atlantic right whale (VAQS20181005Eg / 3893; see Table 4); cause of death: confirmed chronic entanglement. $(\mathrm{a}, \mathrm{b})$ Chronically entangling line embedded into the base of the right flipper (humerus) creating a partial amputation of the limb with surrounding exuberant soft tissue proliferation visible in (b). (c) CT of right radius with arrows indicating areas of bone lysis. Image credits: Virginia Aquarium \& Marine Science Center; CT scan interpretation (arrows) courtesy of

\section{S. Dennison}
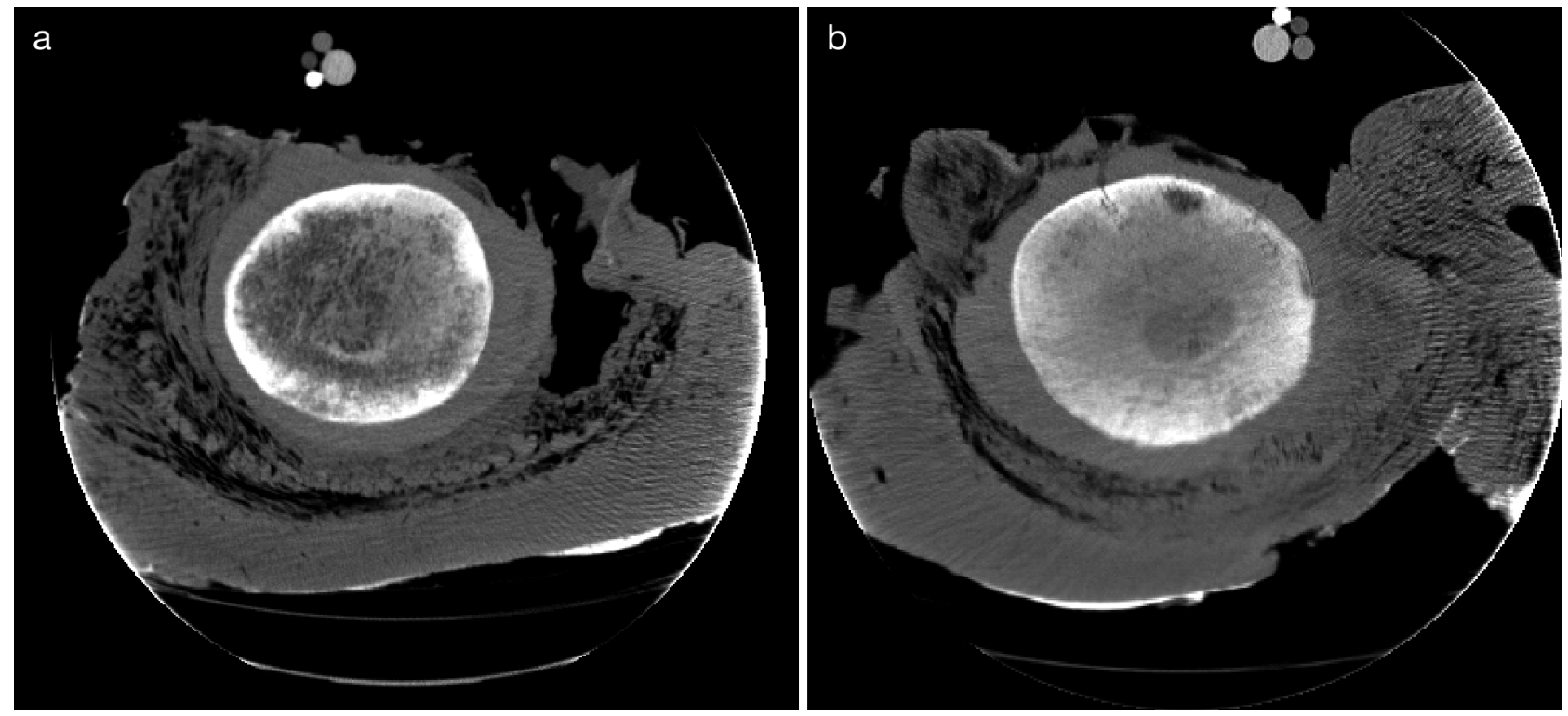

Fig. 21. North Atlantic right whale (EgNEFL1103 / 3911; see Table 4); cause of death: confirmed chronic entanglement. Comparative CT images of right and left humeri at the same level. (a) Entangled flipper shows diminished opacity within the trabecular bone of the diaphysis compared to (b) the unaffected flipper. Image credits: Virginia Aquarium \& Marine Science Center; CT scan interpretation courtesy of S. Dennison

cluding gingival lacerations in some cases. In some of these affected whales, the entanglement configuration would have created a major feeding impediment through physical obstruction of the oropharynx (VAQS2018-1005Eg), decreased efficiency of baleen plate filter feeding (all cases), or entanglementinduced trismus, restricting the ability of the mouth to open when lines to the rostrum were cinched at the flippers (MME16-249Eg). In 1 case, entangling lines created a laceration on the dorsal head, directly into the left naris (blowhole), likely affecting the animal's ability to breathe and possibly its ability to create a water-tight blowhole seal for diving (VAQS2005-1008Eg; Fig. 23b).

Fourteen carcasses, or $63 \%$ of those with entanglement as the proximate COD, were found entangled in gear (Table 5). All of these cases were entangled in multifilament twisted lines or ropes, occasionally with attached polyballs $(\mathrm{n}=4)$, bullet buoys $(\mathrm{n}=1)$, and traps or portions of traps $(\mathrm{n}=2)$. Identifying the gear origin was possible in 5/14 $(35.7 \%)$ cases, all of which were recognized as Canadian snow crab fishing gear. Two of those cases were traced back to a specific region, the Gulf 

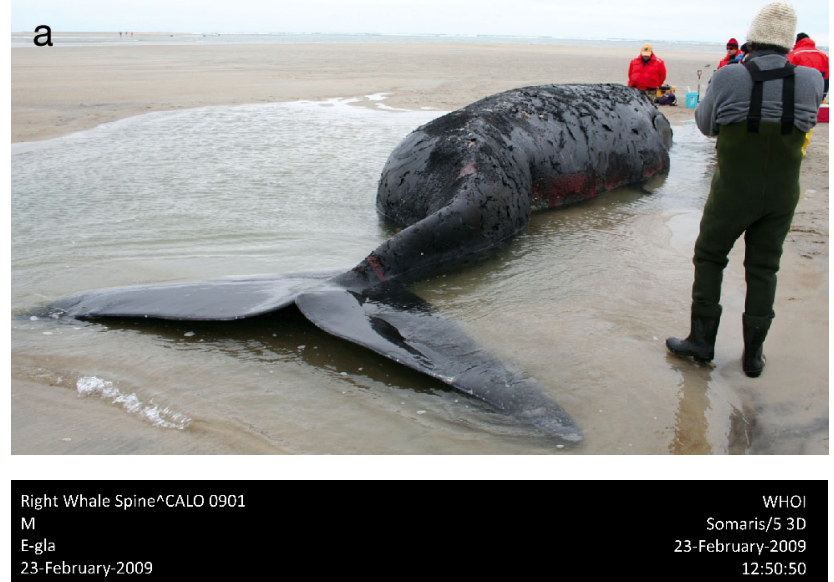

23-February-2009

CT

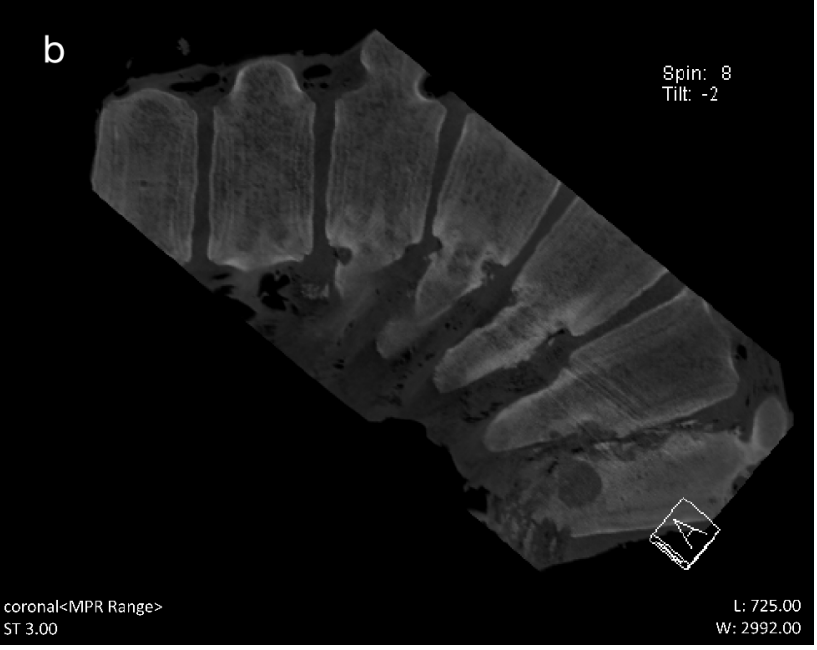

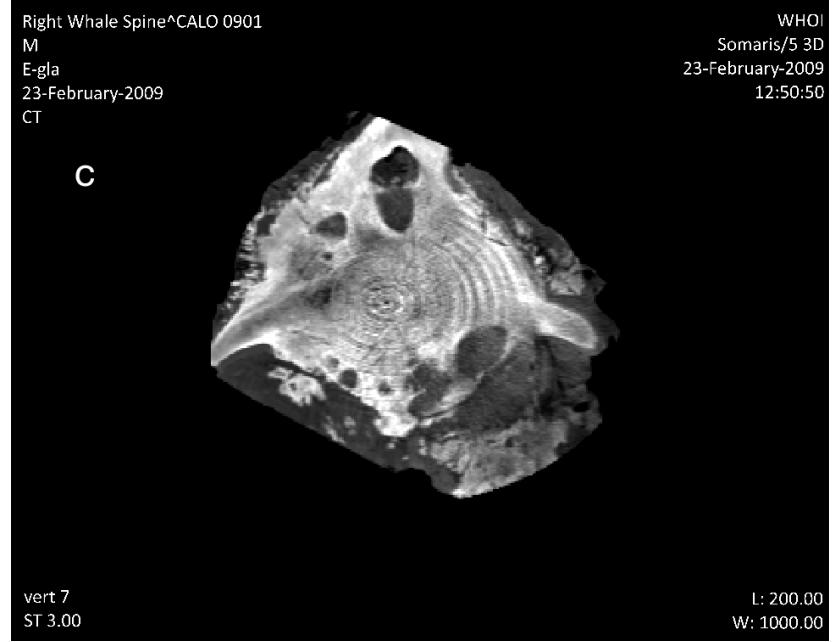

Fig. 22. North Atlantic right whale (CALO 0901 / 3710; see Table 4); cause of death: probable entanglement. (a) Traumatic scoliosis (abnormal curvature of the spine) in situ due to prior entanglement. $(\mathrm{b}, \mathrm{c}) \mathrm{CT}$ scans of affected vertebrae showing significant chronic, predominantly ipsilateral lytic, sclerotic, and proliferative changes of the intervertebral discs, cranial and caudal vertebral end-plates, and vertebral subchondral bone. Image credits: (a) University of North Carolina at Wilmington, (b,c) Woods Hole Oceanographic Institution; CT scan interpretation courtesy of S. Dennison
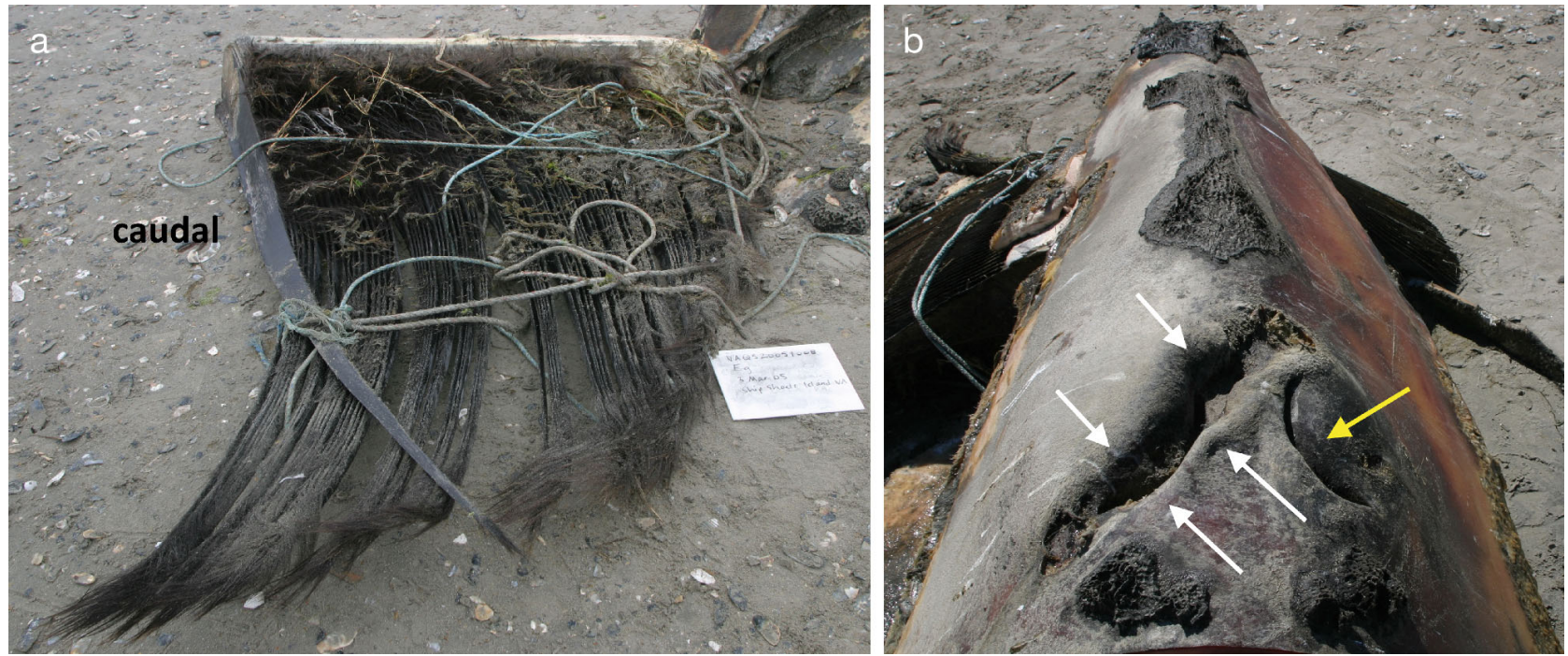

Fig. 23. North Atlantic right whale (VAQS20051008Eg / 2301; see Table 4); cause of death: confirmed chronic entanglement. (a) Anterior half of left baleen rack after gingiva was excised and baleen was reflected to reveal the medial aspect of the baleen and the entangling lines in situ. (b) Deeply abraded laceration (white arrows) directly over the left naris (blowhole) on the dorsal head of the same whale caused by the entangling line. Yellow arrow points to the unaffected right naris (blowhole). Photo credits: Virginia Aquarium \& Marine Science Center 
of St. Lawrence. One additional case was identified as having unknown trap/pot gear of US origin (EgNEFL1235 / 4193) and another case was identified as having unknown trap/pot gear of unknown origin (EgNEFL1103 / 3911). Three cases where only rope was found entangling the whale were not identified to origin at all (SC1118, VAQS20051008Eg, CWHC Incident 86957). Entangling gear from MJM070110Eg / 1124 was lost while under tow to the necropsy site, and 3 additional entangled whales could not be examined or sampled. One of the unexamined entangled whales (IFAW14-156Eg) was possibly entangled and anchored in fixed gear south of Nantucket, MA, USA, based on the presence of a line of floats lying along its body, 2 endlines present in the initial report images, and a stationary position at sea for multiple days. This carcass could not be examined by responders due to poor weather. When conditions improved, fixed gear with large polyballs similar to that documented on the entangled whale were identified at the coordinates of the carcass, but the whale was no longer present. The remaining 9 carcasses listed in Table 5 were not found with gear present; however, the lesions observed at examination were consistent with entanglement in line (based on previously documented cases where line and similar lesions were present), and were sufficiently significant to warrant COD assignation in 8 of those cases. Due to lack of entangling gear available for examination, source of the entangling lines could not be identified in any of these 9 cases.

A whale entangled in gear with attached bullet buoys (EgNEFL1235 / 4193) had weak links present near the base of the buoys, neither of which separated as designed. There were no other intact or broken weak links present in any other gear entangling NARWs documented in this study. The line involved in entanglements was often 5/8" (15.9 mm) and a combination of leaded and unleaded line in many cases. In 9 cases, lines were wrapped multiple (up to 30-50) times around an appendage (Fig. 19), the rostrum, or through the baleen (Fig. 23). Of animals with unidentified gear origins, 1 case had a portion that comprised floating trap/pot groundline (EgNEFL1103 / 3911), and both trap/pot floating and sinking lines were identified in another case (VAQS2005-1008Eg / 2301).

Table 5. Presence and origin of entangling gear in all dead entangled North Atlantic right whale cases 2003-2018. NA: not applicable; DFO: Fisheries and Oceans Canada

\begin{tabular}{|c|c|c|c|}
\hline $\begin{array}{l}\text { Report } \\
\text { year }\end{array}$ & Field ID / catalog ID & $\begin{array}{c}\text { Gear } \\
\text { present? }\end{array}$ & Gear origin \\
\hline 2005 & VAQS20051008Eg / 2301 & Yes & Rope of unknown origin \\
\hline 2006 & EGNEFL0603 / 3602 & No & NA \\
\hline 2007 & BRF134 & No & NA \\
\hline 2009 & CALO $0901 / 3710$ & No & NA \\
\hline 2010 & MJM070110Eg / 1124 & Yes & Entangling lines lost during tow, unable to examine \\
\hline 2010 & CWHC X22447-10 / 1113 & No & NA \\
\hline 2011 & EgNEFL1103 / 3911 & Yes & Unknown trap/pot of unknown origin with floating groundline \\
\hline 2011 & SC1118 & Yes & Unknown gear origin \\
\hline 2011 & NCARI006 / 1308 & No & NA \\
\hline 2012 & CWHC Incident \#86957 & Yes & $\begin{array}{l}\text { Large-diameter rope examined by DFO, unable to determine } \\
\text { gear origin }\end{array}$ \\
\hline 2012 & EgNEFL1235 / 4193 & Yes & Unknown trap/pot of US origin \\
\hline 2013 & NCUR130811 /1311 & Yes & Floating carcass; not sampled/examined \\
\hline 2014 & MARS 2014-113 / CBD & Yes & $\begin{array}{l}\text { Floating carcass; not sampled/examined, but a thick } \\
\text { entangling line is evident in images }\end{array}$ \\
\hline 2014 & IFAW14-156Eg & Yes & Found in fixed gear in US waters \\
\hline 2016 & MARS 2016-175 / 4320 & Yes & Canadian snow crab fishery \\
\hline 2016 & MME-16-249Eg / 3694 & Yes & Canadian snow crab fishery \\
\hline 2017 & MARS 2017-143, EG20170-04 / 3603 & Yes & Canadian snow crab fishery (Gulf of St. Lawrence) \\
\hline 2017 & IFAW17-320Eg & No & NA \\
\hline 2017 & MARS2017-312, EG2017-09 / 4504 & Yes & Canadian snow crab trap (Gulf of St. Lawrence) \\
\hline 2017 & IFAW17-375Eg & No & NA \\
\hline 2018 & VAQS2018-1005Eg / 3893 & Yes & Canadian snow crab fishery \\
\hline 2018 & IFAW18-244Eg & No & NA \\
\hline 2018 & IFAW18-281Eg / 3515 & No & NA \\
\hline
\end{tabular}




\section{DISCUSSION}

The 3 most significant findings in this study were that (1) the relative prevalence of entanglementrelated NARW deaths increased compared to vessel strike deaths with respect to previously published mortality data (Moore et al. 2004), (2) no natural mortalities were identified in adult or juvenile NARWs, and (3) gross and histopathologic features of the traumatic entanglement and vessel strike lesions were consistent and severe. For the purposes of this discussion, we will first explore CODs and other mortality trends over time, then briefly cover the unusual mortality event of 2017. We will then discuss the significance of the anthropogenic traumatic lesions and the manner in which the affected NARWs died.

\subsection{COD}

During the last $16 \mathrm{yr}$, anthropogenic trauma was the leading cause of mortality in NARWs, similar to the antecedent $32 \mathrm{yr}$ period (Moore et al. 2004). However, the predominant type of anthropogenic trauma shifted from vessel strikes to entanglements in the current dataset (see Table 6 for a comparison of anthropogenic trauma incidence between Moore et al. 2004 and this study). Of the 54 NARW mortalities reported between 1970 and 2002, COD was established in 19 cases: 14 were due to vessel strikes, 4 to entanglements, and 1 perinatal death. Thus, for that time period, $73.7 \%(14 / 19)$ of NARWs died due to vessel strikes while the majority of NARWs with determined CODs from the last $16 \mathrm{yr}$ died due to entanglement $(51.2 \%, 22 / 43)$. The etiology of this shift in the principal anthropogenic COD for NARWs is likely multifactorial, consisting of changes within the shipping and fishing industries as well as whale distribution. Additionally, changes in response effort, diagnostic capabilities, and improvements in image quality in recent years have facilitated additional COD determinations that would not have been possible during the earlier time period.

Potentially contributing to this observed trend, ves-

Table 6. Comparison of diagnosed North Atlantic right whale vessel strike (VS) and entanglement (EN) incidence between this study and Moore et al. (2004)

\begin{tabular}{|lccccl|}
\hline \multirow{2}{*}{ Period } & \multicolumn{4}{c|}{ Diagnosis (n) } & \multicolumn{4}{l|}{ Incidence $\left(\right.$ cases $\left.\mathrm{yr}^{-1}\right)$} & Reference \\
& VS & EN & VS & EN & \\
\hline $1970-2002$ & 14 & 4 & 0.4 & 0.1 & Moore et al. (2004) \\
$2003-2018$ & 16 & 22 & 1 & 1.4 & Present study \\
\hline
\end{tabular}

sel speed restrictions went into effect on 9 December 2008 within US waters. When pre- (1970-2008) and post-ship strike rule cases (2009-2018) were compared for carcasses found in US waters, $75 \%(18 / 24)$ of anthropogenic mortalities were due to vessel strikes ( $25 \%$ to entanglement) prior to the rule implementation, compared to only $23.5 \%$ (4/17) due to vessel strikes afterwards $(76.5 \%$ due to entanglement). Previous studies showed the ship strike rule to be moderately effective at decreasing vessel strike mortalities within active seasonal management areas (SMAs), but vessel strike mortalities just outside inactive SMAs actually increased (van der Hoop et al. 2015). The general recommendation from that study and another (Laist et al. 2014) was to increase the coverage of active SMAs in order to improve the rule's efficacy. The reduced number but continued occurrence of NARW deaths in US waters due to vessel strikes reported in this study supports this recommendation as well, indicating that the ship strike rule may have helped to reduce NARW vessel strike mortalities in US waters, but it did not prevent them completely. The spatiotemporal data presented in Table 3 and carcass locations in Table S1 can help inform future geographically and seasonally based management schemes. Moving forward, it is unclear how the new generation of super container ships and the associated trend of wider and deeper ports and channels may impact the whales or the efficacy of the ship strike rule. These larger vessels may require more time and space to execute response maneuvers, which may increase the likelihood of interactions with whales, and (due to reduced maneuverability) they may also have higher navigational safe speeds (an exemption in the ship strike rule), which may increase the likelihood of those interactions being fatal for the whale.

Unlike the observed decrease in NARW vessel strike mortalities, the incidence of entanglement deaths increased since 2008, with 13 documented NARW entanglement deaths discovered in US waters over the last $10 \mathrm{yr}\left(1.3 \mathrm{yr}^{-1}\right)$, compared to 6 in the prior $38 \mathrm{yr}\left(0.16 \mathrm{yr}^{-1}\right)$. When Canadian NARW deaths are included, total entanglement deaths increase to 19 from $2009-2018\left(1.9 \mathrm{yr}^{-1}\right)$ and 7 from $1970-2008\left(0.18 \mathrm{yr}^{-1}\right)$. A portion of this marked recent increase in entanglement deaths may be due to improved efforts in surveillance, reporting, carcass retrieval, and forensic investigations. However, this order of magnitude change in annual entanglement mortality rate is likely 
not due to increases in effort and diagnostic capability alone. In fact, considering the declining NARW population numbers since 2010, the actual risk of entanglement mortality for a given NARW may have increased even more substantially. In agreement with previous studies (Knowlton et al. 2012, Pace et al. 2014, McDonald et al. 2016), these data elucidate the fact that entanglement mitigation measures undertaken by the USA since 1997 as part of the Atlantic Large Whale Take Reduction Plan (NMFS 2014), including gear modifications (weak links, sinking groundlines, minimum trap number per string, gear marking) and seasonal closures, have failed to decrease the number of whale entanglement deaths. While these efforts likely prevented some mortalities (by reducing line suspended in the water column near whales, sinking groundline and seasonal closures are likely worthwhile efforts), they are not sufficient to reduce entanglement-related NARW deaths to the required levels under the US Marine Mammal Protection Act and the Endangered Species Act. In Canadian waters, the Canadian Recovery Strategy and proposed Action Plan (DFO 2016) for this species identifies reducing the threat of fishing gear interactions as one of the highest priority actions to recover this species. Despite this being identified for decades, there have been very limited actions undertaken in Canada to address this threat, and most by non-government, industry, or academic stakeholders. Mandated measures to reduce this threat were only introduced by the federal government in 2018. It is also important to reiterate concerns raised by Moore et al. (2004), about weight loss in chronically entangled whales, who can become negatively buoyant and can be under-represented in the case analysis. Thus, the preponderance of acute entanglement cases in this case series is likely strongly biased by that phenomenon.

Weak links were found in the gear attached to a dead entangled whale in this report (EgNEFL1235); both were intact (did not release). The cause of their release failure was not clear, but could have been due to poor execution (improper configuration when employed at sea), inherent design deficiencies, or insufficient strain being applied at the site of the weak link. Given that the weak links in this case were not located at a point of strain within the entanglement configuration at the time of necropsy, the likelihood that they would have been effective in preventing the entanglement even if they had separated properly was minimal. Another gear modification, the 2015 vertical line rule that established a minimum number of traps per trawl, may have had unintended detrimental consequences for whales by causing fishermen to employ stronger ropes in order to sustain the increased load of hauling multiple traps per trawl (Hayes et al. 2018a). Entanglement injury severity in NARWs has been shown to increase with stronger ropes (Knowlton et al. 2016). Thus, while this modification did reduce overall line in the water column, by replacing it with fewer stronger lines, it may have actually increased related mortalities. These challenges with line modifications illustrate that any line in the water column poses a threat to whales, and mitigation efforts would be more appropriately focused on eliminating ropes from whale habitat entirely (Johnson et al. 2005).

The specific origin of entangling gear was identified in 5/14 cases (Canadian snow crab fishery) while trap/pot gear of either US or unknown origin was identified in 2 additional cases, and a fixed-gear fishery in US waters was suspected in another case. In general, when identified, the entanglements were found to be from fixed fishing gear set within the range of the species. These findings are consistent with a previously published study wherein the main types of gear entangling whales were identified as pot and gill net gear, with NARWs more commonly entangled in the former (Johnson et al. 2005). Gear marking to indicate fishery of origin was not evident in the majority of the 14 cases where gear was present. Improvements in coordinated gear marking locations and redundancies within both Canadian and US fisheries could provide significant insight into proper target fisheries for management efforts. However, the highest fisheries management priority must be minimizing exposure to and interaction of whales with fishing gear altogether.

Management changes not only did not decrease NARW entanglement deaths, but an apparent increase thereof was observed over the study period. This recent entanglement mortality escalation could be partially explained by altered geographic distributions for both NARWs and pot/trap fishing gear, resulting in an increased spatial overlap of the 2 entities. NARWs have been shifting their distribution northward in recent years, with decreased sightings in the southeastern USA and increased sightings in the Gulf of St. Lawrence (Davis et al. 2017, MeyerGutbrod et al. 2018). Changes in whale distributions are largely driven by shifts in prey availability, which in turn are linked to environmental parameters (Meyer-Gutbrod \& Greene 2014, 2018, Meyer-Gutbrod et al. 2015). American lobster distribution has also shifted to the north and offshore in recent years into deeper, cooler waters as previously suitable 
habitat has warmed (Le Bris et al. 2018). Not surprisingly, the lobster fishing industry followed (Pinsky \& Fogarty 2012), increasing the amount of gear in offshore whale habitats. Fishing operations in these harsher environments require more durable fishing gear, resulting in the deployment of stronger, thicker line, the consequences of which have already been discussed.

Knowlton et al. (2012) showed that the annual percentage of NARWs observed with rope present on the body increased significantly over their study period (1980-2009), while the rate of new entanglement wounds did not, suggesting that whales more recently experienced increasing difficulty freeing themselves from entanglement (but not necessarily a higher rate of new entanglement). This finding could be correlated with more durable gear being employed by the fishing industry. The present study shows clearly that the entanglement mortality rate has increased in recent years, but further investigation is warranted to better understand whether this is due to increased rates of entanglement events and/or increased risk of death from entanglement due to changes in gear or other factors. Regardless of the exact mechanism, the efficacy of entanglement mitigation efforts must be improved. As climate change is expected to introduce more variability in the coming years, it is becoming increasingly important to consider environmental parameters during mitigation planning. This is especially true with regards to frequently employed spatially and temporally fixed protection strategies such as 'critical habitat' and 'seasonal management areas.' The efficacy of these approaches may decrease with increased variability in environmental conditions and whale habitat use patterns.

Whales are at risk of becoming entangled any time line is present within the water column in their proximity. Expanding seasonal closures to include a larger percentage of NARW habitat may be part of a more efficacious solution, as would a more dynamic fisheries management strategy based on whale presence (as was employed in the Gulf of St. Lawrence snow crab fishery during the summer of 2018). Ropeless fishing, which either completely eliminates the presence of buoy lines or limits them to when the traps are actively being hauled is also a promising potential solution (Moore 2019). Its success depends upon developing affordable technologies and the willingness and feasibility of the industry to employ it. Knowlton et al. (2016) postulated that widespread adoption of fishing ropes with a breaking strength of $\leq 1700$ lbsf $(\sim 7.56 \mathrm{kN})$ could reduce life-threatening entanglements in all large whales by $72 \%$ by reducing the rope strength to below swimming whale force production (Arthur et al. 2015). While weaker lines may help to decrease entanglement mortalities in adult NARWs, they would likely still have negative impacts on their reproductive health, energetic costs, and chronic stress levels. Additionally, reduced breaking strength line would likely not significantly reduce entanglement mortalities in smaller marine species, specifically endangered leatherback sea turtles (James et al. 2005), minke whales, juvenile humpback whales (Knowlton et al. 2016), and even potentially young NARWs.

\subsection{Other mortality trends}

Over the past $16 \mathrm{yr}$, there were no documented natural mortalities for adult or juvenile NARWs, and more adult NARWs died than juveniles and calves combined. These demographics are in stark contrast to those published by Kraus (1990), who showed that between 1977 and 1985, only 4/25 (16.0\%) mortalities occurred in whales $>12 \mathrm{~m}$ (adults) and that most mortalities occurred in whales under $4 \mathrm{yr}$ of age. While these high mortality rates in young whales were detrimental to population growth, adult females are the most important reproductive demographic and in recent years have experienced the highest mortality rate. This unfortunate statistic likely contributed to the observed poor population growth in this critically endangered species and will continue to do so unless effective mitigation measures are implemented. Additionally, anecdotal data suggesting that NARWs are growing more slowly in the current decade could not be supported here due to small sample size since $2010(\mathrm{n}=2)$. However, for the 2 young whales with available data that died during this decade ( $885 \mathrm{~cm}$ at $2 \mathrm{yr}$ and $1130 \mathrm{~cm}$ at $5 \mathrm{yr}$ ), their straight lengths were shorter than anticipated for their age based on the age-length curves from the prior decades of data.

The calculated potential biological removal (PBR) is the estimated maximum number of animals that can be removed from a marine mammal stock by human activities each year while allowing the stock to reach its optimal sustainable population level. For NARWs, PBR has ranged from 0 to 0.9 over the study period (Hayes et al. 2018b). Over the past $16 \mathrm{yr}$, we documented an annual minimum average of 2.4 known NARWs killed by human-induced trauma (38 deaths in $16 \mathrm{yr}$ ), which is unsustainable for this population. While both entanglement and vessel strike 
deaths are unintentional, they are no less fatal than commercial whaling is, and in many cases, are far less humane (Moore 2014). This exceedance of PBR also does not take into account the additional 27 dead NARWs during that time period for which a COD could not be determined, suggesting that the humaninduced mortality rate within this population could be up to 4 whales annually. It also does not include those NARWs determined to have a serious anthropogenic injury that would likely lead to death that are not represented in this dataset (Henry et al. 2017), again indicating that these numbers are a gross underestimation of the human-induced mortality in this endangered species.

Finally, reported whale carcasses likely represent only a portion of those that actually occur due to the low likelihood of finding carcasses at sea and the reluctance and/or unawareness of various parties to report mortalities to the proper authorities when found (Henry et al. 2013). Knowlton \& Kraus (2001) suggested that the number of unreported NARW deaths is likely equal to the number reported, suggesting that the 70 deaths documented here were likely closer to 140 deaths over $16 \mathrm{yr}$ (8.8 dead NARWs $\mathrm{yr}^{-1}$ ), a grossly unsustainable mortality rate for a population of 411 whales. Further, it is likely that the unreported deaths are biased towards entanglements. Often, vessel-struck animals are in robust condition and their carcasses float and can therefore be detected. In contrast, whales that have been chronically entangled tend to be thinner and their carcasses are more likely to sink, as discussed in Section 4.1 .

\subsection{Unusual mortality event 2017-2018}

The year with the highest number of NARW mortalities was 2017 ( $\mathrm{n}=17$ ), with 12 of the deaths documented in the Gulf of St. Lawrence, Canada, and the other 5 in the USA. Five of the 2017 deaths were attributed to vessel strikes and 4 to entanglements (Daoust et al. 2017, NMFS 2019). NOAA declared an unusual mortality event (UME) for NARWs from 1 January 2017, which was ongoing during the preparation of this manuscript in 2019 (NMFS 2019). The current total number of mortalities included in the event at the time of publication was 20 whales, including 3 NARW carcasses documented off Massachusetts in 2018. Of these 20 whales, 12 were examined by necropsy. The preliminary cause of the event was attributed to human interactions from vessel strikes $(n=5)$ or rope entanglement $(n=7)$. An addi- tional NARW skull fragment uncovered on Martha's Vineyard, MA, in 2018 had not been included in the UME at the time of publication due to its undetermined timeline. The increase in Canadian NARW deaths in 2017 compared to other years likely reflects the northerly NARW distributional shift into unprotected waters, but increased surveillance effort may have also played a role in amplifying mortality reporting. Active monitoring of NARW habitat shifts through aerial and vessel-based surveys and passive acoustic monitoring is imperative to ensure that mitigation measures are adaptive, dynamic, and implemented in the most impactful locations.

\subsection{Necropsy effort}

The majority of cases in this dataset $(51 / 70,73 \%)$ were found floating offshore, compared to Moore et al. (2004) in which only $30 \%$ (16/54) were. While this trend may in large part be due to increased offshore surveillance effort, a possible shift to more offshore whale distributions or mortality factors may also be partially responsible. Regardless, these data strongly support continued and expanded efforts to survey offshore habitat for NARW carcasses in order to obtain more accurate mortality statistics. The efforts put forth to document and when possible, tow, land, transport, and necropsy these whales have been substantially improved in recent years. The ability of stranding networks to prioritize the collection of event, animal, necropsy, and ancillary diagnostics data from this endangered species is evident in the quantity and quality of data available for this study. Increased federal funding in both the USA and Canada for stranding networks engaged in these activities has been, and will continue to be, a critical factor in the ability to monitor NARW mortality events.

Significant improvements in the quality and standardization of data and sample collection since the prior necropsy summary by Moore et al. (2004) are largely due to the NARW necropsy protocol established by McLellan et al. (2004) and the dedicated efforts of Necropsy Team Leaders and stranding organizations along the North American eastern seaboard. As a result of these monumental efforts on the part of all involved, a significant series of NARW trauma cases was able to be compiled here, including the discovery of severe and consistent gross and histopathologic lesions derived from anthropogenic trauma. Efforts to standardize diagnostic procedures, nomenclature, and training should continue to be supported in order to maintain and improve the cur- 
rent state of NARW forensic investigations. Specifically, a standardized method for evaluating body condition in right whale carcasses should be developed. Pettis et al. (2017b) used a scale of good, fair, or poor body condition in free-swimming right whales based on the dorsal profile posterior to the blowholes. This approach may be adaptable to floating and stranded whales but is likely limited by carcass recumbency and postmortem bloating. More preferably, a 5-point numerical scale based on multiple anatomical locations, as is commonly used on other species, should be developed to better evaluate body condition in these cases. McLellan et al. (2004) also stressed that a comprehensive collection of blubber thicknesses across the entire body surface provides the best description of a whale's nutritional status and body condition.

\subsection{Traumatic lesions}

Histopathologic lesions observed in some propeller strike cases (discoid and segmental disintegration of myofibers) were consistent with lesions observed in experimentally traumatized skeletal muscle exposed to seawater (Stacy et al. 2015) and with those reported in large whales by Sierra et al. (2014), indicating that perimortem propeller injuries can be identified in whale carcasses even when wounds have been washed out by seawater. In fact, the study by Stacy et al. (2015) illustrated that seawater exposure increases detectability of discoid and segmental disintegration in muscle injuries caused during the perimortem/supravital period. These results indicate that washout areas may be the best region to sample for myofiber damage evidence, and it is strongly encouraged that prosectors prioritize washout regions of suspect propellerinduced lesions for histopathology in future cases. Fat emboli, which are commonly associated with traumatic (especially orthopedic) injuries (Hulman 1995) and have been observed in whales with evidence of barotrauma (Fernández et al. 2005), were not observed in any of the carcasses in this study. The significance of their absence is unclear, as fat emboli are usually released from the marrow (which is largely absent in whales) exposed in long-bone fractures, and barotrauma fat emboli are likely associated with gas embolus formation within fatty tissues. Techniques such as oil red O and Sudan black staining, osmium tetroxide postfixation, and paraffin embedding were also not regularly employed to detect fat emboli.
The focal patchy to undulating pattern of blubber contusion observed in a portion of the vessel strike blunt trauma cases could have a few different etiologies: (1) shearing forces from the vessel impact may tear cutaneous trunks of vessels crossing through the subdermal sheath; (2) compressive forces due to vessel hull features may result in focal extravasation along pressure points; or (3) the undulating pattern is similar to that made when experimental shock waves travel through tissues with varying densities and thus variable resulting wave velocities (Clemedson \& Jönsson 1961, Cernak 2017). If focal regions of patchy or undulating blubber contusions are documented during a necropsy, the prosector should look for other supportive evidence of blunt trauma. Efforts to understand vascular supply patterns (e.g. angiosomes) of different regions may help reduce conflation of livor mortis and postmortem marbling with perimortem traumatic edema and hemorrhage.

The putty-like substance observed in many blunt trauma cases as described in this study was reported in 1 NARW carcass previously (Moore et al. 2004); this animal was also a victim of severe blunt trauma. Suggestive of massive internal hemorrhage, the substance's origin is consistent with blood clots that have coagulated and lysed under the heat and increased internal body pressure resulting from decomposition within a carcass of large mass. However, caution must be undertaken not to over-interpret this finding on necropsies of animals in advanced decomposition, since severely autolyzed muscle and other tissues may have a similar appearance and consistency, and decomposition or environmental effects (e.g. mechanical trauma from waves) may cause postmortem organ rents and release of blood into cavities. Dependent surface changes from death to bloating to stranding and necropsy are also important to consider in the differentiation of true perimortem hemorrhage patterns from postmortem lividity. While NARW carcasses tend to float in dorsal or lateral recumbency, vessel interactions, especially propeller trauma, can affect the orientation of floating whales after death. Presence of 'putty' is supportive of perimortem hemorrhage from blunt trauma when present along fracture lines, in discrete interstitial pockets (e.g. intramuscularly), or in conjunction with other traumatic lesions but should not be used as the sole indicator of blunt trauma in whale carcasses. Efforts should also be made not to confuse clots of vascular origin with 'putty.' In a case with advanced decomposition and an undetermined COD (MARS 2017-144/EG2017-03), degraded muscle and connective tissue were found within a portion of similar- 
looking putty-like substance, making it impossible to determine the etiology of the material (muscle or a combination of blood and muscle) and thus hindering the interpretation of this finding in that particular case. This case highlights the challenges of drawing diagnostic conclusions from gross and microscopic examinations of NARW carcasses in advanced decomposition. In many of these cases, the gross lesions will be the most helpful in determining COD, especially when there are multiple gross lesions in support of the same etiology (see Moore et al. 2013 for anthropogenic trauma case criteria definitions). While histopathologic investigation is hindered by autolysis in cases of advanced decomposition, it can provide supportive evidence for gross conclusions and is still a valuable tool to employ in these important cases. Another noteworthy limitation of necropsies on animals in advanced decomposition is that underlying toxicoses and infectious diseases may be more difficult to rule out. While samples were analyzed for presence of biotoxins in some NARW cases, associated gross and histopathologic lesions may not have been evident due to decomposition. Conditions such as encephalitis, hippocampal atrophy, or other CNS pathologies are nearly impossible to diagnose in large whales due to how rapidly these tissues degrade after death. While this does not detract from the severity of the observed traumatic lesions, it does limit our understanding of other potential co-morbidity factors in this species.

Previous publications have reported rope embedded in bones of entangled large whales, similar to our findings (Moore et al. 2004, 2006, Cassoff et al. 2011). Moore et al. (2004) also reported 2 chronic entanglement cases in NARWs with diffuse soft tissue ossification around the site of flipper entanglement, but lesions in both cases were lost during museum preparation. Ours is the first study to present a case series of osteopathic lesions indicative of chronic entanglement-induced trauma in NARWs to include periosteal proliferation (exuberant new bone growth in response to relentless insult), osteopenia (due to presumed flipper disuse), lytic lesions (potentially from osteomyelitis or osteonecrosis), and osseous metaplasia (formation of bone-like material in soft tissues). Osteopenia and lytic bone lesions were most readily identified with bone imaging (CT scanning), which was only performed in 2 entanglement cases (CALO 0901 and VAQS20181005Eg). Retrieval of entangled flippers and the unaffected contralateral control specimens should be a priority for future necropsies to provide an age-appropriate 'normal' for comparison in advanced diagnostic imaging to more accurately evaluate the severity of the induced lesions in the affected flipper. Additionally, continued sampling of colonic contents to determine overall stress hormone levels (Rolland et al. 2017) aids in providing an endocrine-based context for the necropsy results.

This compilation of significant gross and histopathologic findings in NARW trauma cases indicates that despite some loss of evidence in the interval between death and carcass recovery, diagnoses are still possible if a careful examination and sampling are undertaken. Obtaining and labeling detailed samples of suspected traumatic injuries will offer the opportunity to categorize these lesions as antemortem, perimortem, or postmortem. However, experience with prosection and gross pathologic interpretation are invaluable due to previously mentioned challenges related to interpreting histopathologic samples with significant autolysis. Additionally, better understanding of wound vitality characteristics may help improve sampling locations and inform interpretations of perimortem interval. These efforts will enable prosectors to more frequently and accurately establish a COD and estimate time of injury relative to death.

While not necessarily traumatic lesions, the multifocal glossal ulcers observed in 2 cases in our study were interestingly observed in a previously reported case (Catalog Eg \#1014 'Staccato') that died from vessel strike in 1999. Prosectors are encouraged to sample and perform full diagnostics on such lesions (pan-viral screening and/or electron microscopy) in the future in order to better understand the etiology of these lesions and any potential impact on NARW health.

\subsection{Manner of death}

Trauma was severe in the 38 NARWs that died due to human activities. Some mortalities were likely acute, such as vessel strike blunt trauma cases where massive skull fractures likely caused loss of consciousness and rapid death. Other vessel-struck whales died due to exsanguination and resultant hypovolemic shock or traumatic pneumo- or hemothorax. While not extremely protracted, these mechanisms of death are not considered humane according to the AVMA Guidelines for the Euthanasia of Animals (Leary et al. 2013). One propeller-struck whale with a completely severed caudal peduncle and flukes (EgNEFL0602) presumably lost its ability to locomote efficiently if not altogether, and either 
drowned as a result of its inability to remain at the surface or died from hypovolemic shock due to exsanguination. As previously described by Moore et al. (2013) and Cassoff et al. (2011), peracute underwater entrapment occurring when animals entangled in gear could not reach the surface to breathe was likely a relatively acute death. The necropsies of many of these cases showed evidence of a significant antemortem struggle, including marked contusions and edema from thrashing against the entangling gear and fluid within the lungs from either terminal aspiration or asphyxia. Based on these findings, it is reasonable to assume that a considerable amount of stress and pain would be experienced by the whale prior to its demise from peracute underwater entrapment in entangling gear.

Chronic injuries were sustained by whales that carried entangling gear for long periods of time. Over time, the impinging line on flippers, peduncle, head, and body created deep lacerations into the underlying soft tissue and bone, often with surrounding hemorrhage and edema. In some chronic cases where rope movement against the body surface was minimal, scar tissue formed over the entangling line, encasing it as a potential nidus of infection within the surrounding tissue. Both the soft tissue and osteopathic lesions observed in chronically entangled whales would be profoundly painful and debilitating over time (Moore et al. 2006, Cassoff et al. 2011, Moore 2013).

The poor health of many of these chronically entangled whales was also reflected in their increased cyamid burden and poor body condition. Furrows created by entanglement lesions and poor skin condition provide protective habitat for these obligate parasites, and it has been postulated that whales debilitated by the sequelae from a long-term entanglement may swim slower, increasing the available low-flow habitat for cyamids on the whale's body (Osmond \& Kaufman 1998, Pettis et al. 2004). Lower swim speeds in these whales would also impact their ability to consume sufficient calories in any given period of time. Additionally, the direct impediments of baleen plate separation, mutilation, and oral cavity obstruction due to entangling line are unquantified to date, but likely have a substantial impact on the ability of a filter-feeding animal to forage and thermoregulate efficiently (Werth 2004, Lambertsen et al. 2005, Kot et al. 2009, Ford et al. 2013).

Finally, the chronic implications of even acute traumatic events, especially in young growing animals, are evident from the cases presented here. Despite never being observed carrying gear, CALO0901 /
3710 had protracted traumatic insults (traumatic scoliosis) from a prior entanglement event that compromised his mobility and ability to feed over a year after its apparent resolution, eventually leading to his live stranding and necessary euthanasia (Harms et al. 2014). Both this case and that of the NARW (NEFL0501Eg / 2143) with healed propeller lacerations whose subsequent pregnancy re-opened her wounds and led to her death 14 yr after the instigating injury, are morbid reminders that even seemingly resolved traumatic events caused by human activities can have unseen and profound impacts on this species' survival.

\section{CONCLUSION}

If the recent trends presented here are not sufficient to instigate meaningful change within NARW habitat, their extinction is almost certain. This dataset agrees with Corkeron et al. (2018) that adult NARWs are not dying from geriatric conditions because they are instead suffering premature deaths due to human-induced trauma. Young whales are also dying from anthropogenic trauma at an alarming rate, further limiting the number of NARWs reaching sexual maturity and reducing the potential for population recovery. Some of the deaths caused by human activities inflict painful acute deaths, while others are much more protracted, causing a profound amount of suffering for each affected whale. It is essential that measures to reduce anthropogenic NARW mortality be undertaken immediately, as was previously called for nearly 14 yr ago by Kraus et al. (2005). If mitigation efforts such as more effective gear modifications, extended fishery closures, and expanded vessel speed restrictions are not implemented imminently, human activities will cause an inhumane and certain extinction of this species in the all-too near future.

Acknowledgements. In the USA, this investigative work was conducted under NOAA Marine Mammal Health and Stranding Response Permits 932-1489, 932-1905, 17355, and 18786. Canadian investigations were conducted under Section 73 SARA permits issued by Fisheries and Oceans Canada (DFO-MAR-2016-02 Amendment 1) to relevant Canadian response organizations. Great thanks are owed to the NARW community and specifically the NARWC and its contributing membership for sharing data and expertise. This study only exists because of the work of stranding responders, volunteers, and government partners along the Northwest Atlantic seaboard who handle the overwhelming logistical challenge of towing, landing, transporting, and necropsying these whales. Additional thanks for necropsy and ancillary data are owed to Bob Bonde, Craig Harms, 
Lynda Doughty, Misty Niemeyer, Kristy Volker, Karen Sayles, Michael Walsh, Mendy Garron, Sean Todd, Jerry Conway, Jack Lawson, Wayne Ledwell, Robert Michaud, Stephane Lair, Stephanie Ratelle, Benjamin Lamglait, Andrew Reid, Wayne McFee, and James Powell. There was extensive support for the 2017 mortality event in Canada and additional people and organizations are acknowledged in the incident report (Daoust et al. 2017). The Atlantic Large Whale Disentanglement Network responded to and provided data regarding entanglements of live and dead NARWs. Scott Landry (Center for Coastal Studies) provided entanglement reconstructions based on postmortem data as well as valuable comments on the manuscript. The aerial survey teams in both the USA and Canada (NOAA Northeast Fisheries Science Center, Center for Coastal Studies, New England Aquarium, Sea to Shore Alliance, Florida Fish and Wildlife, University of North Carolina Wilmington, Department of Fisheries and Oceans Canada, and others) provided live whale sightings data and carcass reports and tracking. Thanks to Allison Henry for edits to Table S1. The Anderson Cabot Center for Ocean Life at the New England Aquarium analyzed and interpreted the fecal glucocorticoid data. Sophie Dennison, DACVR provided CT image interpretation. Thanks to Katie Gilbert and Kirsten Spray for their assistance with data organization and entry into the NARW necropsy database and Ashley Powell for her help with Canadian case study summaries. Gaia Bonini provided the ArcGIS maps. Funding for this case review study was provided in part by a grant from CINAR (NA14OAR432 0158). Necropsy and sample analysis expenses were funded by a combination of stranding network budgets, the Canadian Wildlife Health Cooperative, the Government of Canada Habitat Stewardship Program for Species at Risk (MARS), and federal funds from NOAA MMHSRP and Fisheries and Oceans Canada. Funding for the US 2017-2018 UME cases was provided by NOAA MMHSRP and UME Contingency Fund. The scientific results and conclusions, as well as any views or opinions expressed herein, are those of the authors and do not necessarily reflect the views of NOAA.

\section{LITERATURE CITED}

Arthur LA, McLellan WA, Piscitelli MA, Rommel SA and others (2015) Estimating maximal force output of cetaceans using axial locomotor muscle morphology. Mar Mamm Sci 31:1401-1426

Bannister JL, Hammond PS, Double MC (2016) Population trend in right whales off southern Australia 1993-2015. Rep Int Whal Comm SC/66b/BRG09. International Whaling Commission, Cambridge

Cassoff RM, Moore KM, McLellan WA, Barco SG, Rotstein DS, Moore MJ (2011) Lethal entanglement in baleen whales. Dis Aquat Org 96:175-185

Caswell H, Fujiwara M, Brault S (1999) Declining survival probability threatens the North Atlantic right whale. Proc Natl Acad Sci USA 96:3308-3313

Cernak I (2017) Understanding blast-induced neurotrauma: How far have we come? Concussion 2:CNC42

* Clemedson CJ, Jönsson A (1961) Transmission of elastic disturbances caused by air shock waves in a living body. J Appl Physiol 16:426-430

Cooke JG (2018) Eubalaena glacialis. IUCN Red List of Threatened Species 2018: e.T41712A50380891. http://
dx.doi.org/10.2305/IUCN.UK.2018-1.RLTS.T41712A50 380891.en (accessed 4 Feb 2019)

Cooke JG, Rowntree VJ, Sironi M (2015) Southwest Atlantic right whales: interim updated population assessment from photo-id data collected at Península Valdéz. Rep Int Whal Comm SC/66a/BRG 23. International Whaling Commission, Cambridge

Corkeron P, Hamilton P, Bannister J, Best P and others (2018) The recovery of North Atlantic right whales, Eubalaena glacialis, has been constrained by humancaused mortality. R Soc Open Sci 5:180892

Daoust PY, Couture EL, Wimmer T, Bourque L (2017) Incident Report: North Atlantic right whale mortality event in the Gulf of St. Lawrence, 2017. Canadian Wildlife Health Cooperative, Marine Animal Response Society, and Fisheries and Oceans Canada. http://publications.gc. $\mathrm{ca} / \mathrm{pub}$ ? id $=9.850838 \& \mathrm{sl}=0$

Davis GE, Baumgartner MF, Bonnell JM, Bell J and others (2017) Long-term passive acoustic recordings track the changing distribution of North Atlantic right whales (Eubalaena glacialis) from 2004 to 2014. Sci Rep 7: 13460

DFO (Fisheries and Oceans Canada) (2014) Recovery strategy for the North Atlantic right whale (Eubalaena glacialis) in Atlantic Canadian Waters [Final]. Species at Risk Act Recovery Strategy Series. Fisheries and Oceans Canada, Ottawa

DFO (2016) Action plan for the North Atlantic right whale (Eubalaena glacialis) in Canada: fishery interactions [Proposed]. Species at Risk Act Action Plan Series. Fisheries and Oceans Canada, Ottawa

*Fernández A, Edwards JF, Rodriguez F, Espinosa de los Monteros A and others (2005) 'Gas and fat embolic syndrome' involving a mass stranding of beaked whales (family Ziphiidae) exposed to anthropogenic sonar signals. Vet Pathol 42:446-457

Findlay K, Thornton M, Wilkinson C, Vermeulen E, Hoerbst S (2017) Report on the 2016 Mammal Research Institute whale unit southern right whale survey, Nature's Valley to Lambert's Bay, South Africa. Rep Int Whal Comm, SC/67a/SH05_rev1. International Whaling Commission, Cambridge

Ford TJ, Werth AJ, George JC (2013) An intraoral thermoregulatory organ in the bowhead whale (Balaena mysticetes), the corpus cavernosum maxillaris. Anat Rec 296: 701-708

* Fortune SME, Trites AW, Perryman WL, Moore MJ, Pettis HM, Lynn MS (2012) Growth and rapid early development of North Atlantic right whales (Eubalaena glacialis). J Mammal 93:1342-1354

Frasier TR, Hamilton PK, Brown MW, Kraus SD, White BN (2009) Sources and rates of errors in methods of individual identification for North Atlantic right whales. J Mammal 90:1246-1255

* Frasier TR, Gillett RM, Hamilton PK, Brown MW, Kraus SD, White BN (2013) Postcopulatory selection for dissimilar gametes maintains heterozygosity in the endangered North Atlantic right whale. Ecol Evol 3:3483-3494

Geraci JR, Lounsbury VJ (2005) Marine mammals ashore: a field guide for strandings, $2^{\text {nd }}$ edn. National Aquarium in Baltimore, Baltimore, MD

Hamilton PK, Knowlton AR, Marx MK, Kraus SD (1998) Age structure and longevity in North Atlantic right whales (Eubalaena glacialis) and their relation to reproduction. Mar Ecol Prog Ser 171:285-292 
Harms CA, McLellan WA, Moore MJ, Barco SG, Clarke EO III, Thayer VG, Rowles TK (2014) Low-residue euthanasia of stranded mysticetes. J Wildl Dis 50:63-73

Hayes SA, Gardner S, Garrison L, Henry A, Leandro L (2018a) North Atlantic right whales - evaluating their recovery challenges in 2018. NOAA Tech Memo NMFSNE-247. https://www.greateratlantic.fisheries.noaa.gov/ protected/whaletrp/trt/meetings/September\%202018/tm 247_2_.pdf (accessed on 16 Oct 2018)

Hayes SA, Josephson E, Maze-Foley K, Rosel PE and others (2018b) TM 245 US Atlantic and Gulf of Mexico marine mammal stock assessments - 2017. NOAA Tech Memo NMFS NE-245. https://www.nefsc.noaa.gov/publications/ $\mathrm{tm} / \mathrm{tm} 245 /$ (accessed 16 Oct 2018)

Henry AG, Cole TVN, Hall L, Ledwell W, Morin D, Reid A (2013) Mortality determinations for baleen whale stocks along the Gulf of Mexico, United States east coast, and Atlantic Canadian Provinces, 2007-2011. US Dept Commerce, Northeast Fish Sci Cent Ref Doc 13-18. https:// www.nefsc.noaa.gov/publications/tm/tm245/ (accessed 16 Oct 2018)

Henry AG, Cole TVN, Garron M, Ledwell W, Morin D, Reid A (2017) Serious injury and mortality determinations for baleen whale stocks along the Gulf of Mexico, United States east coast, and Atlantic Canadian Provinces, 2011-2015. US Dept Commerce, Northeast Fish Sci Cent Ref Doc 17-19. https://www.nefsc.noaa.gov/publications/ crd/crd1719/ (accessed 24 Aug 2018)

Hulman G (1995) The pathogenesis of fat embolism. J Pathol 176:3-9

James M, Ottensmeyer C, Myers R (2005) Identification of high-use habitat and threats to leatherback sea turtles in northern waters: new directions for conservation. Ecol Lett 8:195-201

Johnson A, Salvador G, Kenney J, Robbins J, Kraus S, Landry S, Clapham P (2005) Fishing gear involved in entanglements of right and humpback whales. Mar Mamm Sci 21:635-645

Kenney RD (2018) What if there were no fishing? North Atlantic right whale population trajectories without entanglement mortality. Endang Species Res 37:233-237

Khan C, Henry A, Duley P, Gatzke J, Crowe L, Cole T (2016) North Atlantic right whale sightings survey (NARWSS) and right whale sighting advisory system (RWSAS) 2016 results summary. US Dept Commerce, Northeast Fish Sci Cent Ref Doc 18-01. https://www.nefsc.noaa.gov/ publications/crd/crd1801/crd1801.pdf (accessed 18 Feb 2019)

Knowlton AR, Kraus SD (2001) Mortality and serious injury of northern right whales (Eubalaena glacialis) in the western North Atlantic Ocean. J Cetacean Res Manag 2: 193-208

Knowlton AR, Sigukjósson J, Ciano JN, Kraus SD (1992) Long distance movements of North Atlantic right whales (Eubalaena glacialis). Mar Mamm Sci 8:397-405

Knowlton AR, Hamilton PK, Marx MK, Pettis HM, Kraus SD (2012) Monitoring North Atlantic right whale Eubalaena glacialis entanglement rates: a $30 \mathrm{yr}$ retrospective. Mar Ecol Prog Ser 466:293-302

Knowlton AR, Robbins J, Landry S, McKenna H, Kraus SD, Werner TB (2016) Effects of fishing rope strength on the severity of large whale entanglements. Conserv Biol 30: 318-328

Kot BW, Ramp C, Sears R (2009) Decreased feeding ability of a minke whale (Balaenoptera acutorostrata) with entanglement-like injuries. Mar Mamm Sci 25:706-713

* Kraus SD (1990) Rates and potential causes of mortality in North Atlantic right whales (Eubalaena glacialis). Mar Mamm Sci 6:278-291

Kraus SD, Hamilton PK, Kenney RD, Knowlton AR, Slay CK (2001) Reproductive parameters of the North Atlantic right whale. J Cetacean Res Manag (Spec Issue) 2: 231-236

Kraus SD, Brown MW, Caswell H, Clark CW and others (2005) North Atlantic right whale in crisis. Science 309: 561-562

Laist DW, Knowlton AR, Pendelton D (2014) Effectiveness of mandatory vessel speed limitations for protecting North Atlantic right whales. Endang Species Res 23:133-147

Lambertsen RH, Rasmussen KJ, Lancaster WC, Hintz RJ (2005) Functional morphology of the mouth of the bowhead whale and its implications for conservation. J Mammal 86:342-352

Ke Bris A, Mills KE, Wahle RA, Chen Y and others (2018) Climate vulnerability and resilience in the most valuable North American fishery. Proc Natl Acad Sci USA 115: 1831-1836

Leary S, Underwood W, Anthony R, Cartner S and others (2013) AVMA Guidelines for the euthanasia of animals: 2013 edn. American Veterinary Medical Association, Schaumburg, IL. https://www.avma.org/KB/Policies/ Documents/euthanasia.pdf

McDonald SL, Lewison RL, Read AJ (2016) Evaluating the efficacy of environmental legislation: a case study from the US marine mammal Take Reduction Planning process. Glob Ecol Conserv 5:1-11

McLellan WA, Rommel S, Moore M, Pabst DA (2004) Right whale necropsy protocol. Final report to NOAA Fisheries for contract \#40AANF112525. http://citeseerx.ist.psu. edu/viewdoc/download?doi=10.1.1.296.8760\&rep=rep1\& type=pdf (accessed 28 Aug 2018)

McLeod BA, Brown MW, Frasier TR, White BN (2010) DNA profile of a sixteenth century western North Atlantic right whale (Eubalaena glacialis). Conserv Genet 11: 339-345

* Meyer-Gutbrod EL, Greene CH (2014) Climate-associated regime shifts drive decadal-scale variability in recovery of North Atlantic right whale population. Oceanography 27:148-153

*Meyer-Gutbrod EL, Greene CH (2018) Uncertain recovery of the North Atlantic right whale in a changing ocean. Glob Chang Biol 24:455-464

* Meyer-Gutbrod EL, Greene CH, Sullivan PJ, Pershing AJ (2015) Climate-associated changes in prey availability drive reproductive dynamics of the North Atlantic right whale population. Mar Ecol Prog Ser 535:243-258

Meyer-Gutbrod EL, Greene CH, Davies KTA (2018) Marine species range shifts necessitate advanced policy planning: the case of the North Atlantic right whale. Oceanography 31:19-23

Moore MJ (2013) Welfare of whales bycaught in fishing gear or struck by vessels. Anim Welf 22:117-121

Moore MJ (2014) How we all kill whales. ICES J Mar Sci 71: 760-763

Moore MJ (2019) How we can all stop killing whales: a proposal to avoid whale entanglement in fishing gear. ICES J Mar Sci, doi:10.1093/icesjms/fsy194

Moore MJ, Knowlton AR, Krauss SD, McLellan WA, Bonde RK (2004) Morphometry, gross morphology and available histopathology in North Atlantic right whale (Eubalaena 
glacialis) mortalities (1970-2002). J Cetacean Res Manag 6:199-214

Moore MJ, Bogomolni A, Bowman R, Hamilton PK and others (2006) Fatally entangled right whales can die extremely slowly. Proc Oceans 2006, Boston, MA. IEEE Xplore, Washington, DC

Moore MJ, van der Hoop J, Barco SG, Costidis AM and others (2013) Criteria and case definitions for serious injury and death of pinnipeds and cetaceans caused by anthropogenic trauma. Dis Aquat Org 103:229-264

NARWC (North Atlantic Right Whale Consortium) (2018a) North Atlantic Right Whale Consortium necropsy database. New England Aquarium, Boston, MA

NARWC (2018b) North Atlantic Right Whale Consortium identification database. New England Aquarium, Boston, MA

NMFS (National Marine Fisheries Service) (2008) Final rule to implement speed restrictions to reduce the threat of ship collisions with North Atlantic right whales. Fed Regist 73:60173-60191. https://www.federalregister.gov/ documents/2008/10/10/E8-24177/endangered-fish-andwildlife-final-rule-to-implement-speed-restrictions-toreduce-the-threat-of-ship (accessed 28 Aug 2018)

NMFS (2014) Taking of marine mammals incidental to commercial fishing operations; Atlantic large whale take reduction plan regulations - inal rule. Fed Regist 79: 36586-36620. https://www.federalregister.gov/documents/ 2014/06/27/2014-14936/taking-of-marine-mammalsincidental-to-commercial-fishing-operations-atlanticlarge-whale-take (accessed 28 Aug 2018)

NMFS (2019) 2017-2018 North Atlantic right whale unusual mortality event. https://www.fisheries.noaa.gov/national/ marine-life-distress/2017-2018-north-atlantic-right-whaleunusual-mortality-event (accessed 20 Feb 2019)

Osmond MG, Kaufman GD (1998) A heavily parasitized humpback whale (Megaptera novaeangliae). Mar Mamm Sci 14:146-149

Pace RM III, Cole TVN, Henry AG (2014) Incremental fishing gear modifications fail to significantly reduce large whale serious injury rates. Endang Species Res 26: 115-126

* Pace RM III, Corkeron PJ, Kraus SD (2017) State-space mark-recapture estimates reveal a recent decline in abundance of North Atlantic right whales. Ecol Evol 7: 8730-8741

* Pettis HM, Rolland RM, Hamilton PK, Brault S, Knowlton AR, Kraus SD (2004) Visual health assessment of North Atlantic right whales (Eubalaena glacialis) using photographs. Can J Zool 82:8-19

Pettis HM, Pace RM III, Schick RS, Hamilton PK (2017a) North Atlantic Right Whale Consortium annual report card. Report to the North Atlantic Right Whale Consortium, October 2017. NARWC, Boston, MA. https://www. narwc.org/uploads/1/1/6/6/116623219/2017_report_card final.pdf

Pettis HM, Rolland RM, Hamilton PK, Knowlton AR, Burgess EA, Kraus SD (2017b) Body condition changes arising from natural factors and fishing gear entanglements in North Atlantic right whales Eubalaena glacialis. Endang Species Res 32:237-249

Pettis HM, Pace RM III, Hamilton PK (2018) North Atlantic right whale consortium annual report card. Report to the
North Atlantic right whale consortium, November 2018. NARWC, Boston, MA. https://www.narwc.org/uploads/ 1/1/6/6/116623219/2018report_cardfinal.pdf

*Pinsky ML, Fogarty M (2012) Lagged social-ecological responses to climate and range shifts in fisheries. Clim Change 115:883-891

Reeves RR (2001) Overview of catch history, historic abundance and distribution of right whales in the western North Atlantic and in Cintra Bay, West Africa. J Cetacean Res Manag 2:187-192

Rolland RM, Hunt KE, Kraus SD, Wasser SK (2005) Assessing reproductive status of right whales (Eubalaena glacialis) using fecal hormone metabolites. Gen Comp Endocrinol 142:308-317

Rolland RM, Parks SE, Hunt KE, Castellote M and others (2012) Evidence that ship noise increases stress in right whales. Proc R Soc B 279:2363-2368

Rolland RM, Schick RS, Pettis HM, Knowlton AR, Hamilton PK, Clark JS, Kraus SD (2016) Health of North Atlantic right whales Eubalaena glacialis over three decades: from individual health to demographic and population health trends. Mar Ecol Prog Ser 542:265-282

* Rolland RM, McLellan WA, Moore MJ, Harms CA, Burgess EA, Hunt KE (2017) Fecal glucocorticoids and anthropogenic injury and mortality in North Atlantic right whales Eubalaena glacialis. Endang Species Res 34: 417-429

Rommel SA, Costidis AM, Pitchford TD, Lightsey JD, Snyder RH, Haubold EM (2007) Forensic methods for characterizing watercraft from watercraft-induced wounds on the Florida manatee (Trichechus manatus latirostris). Mar Mamm Sci 23:110-132

* Semeraro D, Passalacqua NV, Symes S, Gilson T (2012) Patterns of trauma induced by motorboat and ferry propellers as illustrated by three known cases from Rhode Island. J Forensic Sci 57:1625-1629

* Sierra E, Fernández A, Espinosa de los Monteros A, Arbelo M, Diaz-Delgado J, Andrada M, Herráez P (2014) Histopathological muscle findings may be essential for a definitive diagnosis of suspected sharp trauma associated with ship strikes in stranded cetaceans. PLOS ONE 9:e88780

Stacy BA, Costidis AM, Keene JL (2015) Histologic changes in traumatized skeletal muscle exposed to seawater: a canine cadaver study. Vet Pathol 52:170-175

Tyack PL (2008) Implications for marine mammals of largescale changes in the marine acoustic environment. J Mammal 89:549-558

* van der Hoop JM, Moore MJ, Barco SG, Cole TVN and others (2013) Assessment of management to mitigate anthropogenic effects on large whales. Conserv Biol 27: 121-133

* van der Hoop JM, Vanderlaan ASM, Cole TVN, Henry AG and others (2015) Vessel strikes to large whales before and after the 2008 Ship Strike Rule. Conserv Lett 8:24-32

* van der Hoop JM, Corkeron P, Kenney J, Landry S, Morin D, Smith J, Moore MJ (2016) Drag from fishing gear entangling North Atlantic right whales. Mar Mamm Sci 32: 619-642

*Werth AJ (2004) Models of hydrodynamic flow in the bowhead whale filter feeding apparatus. J Exp Biol 207: 3569-3580 


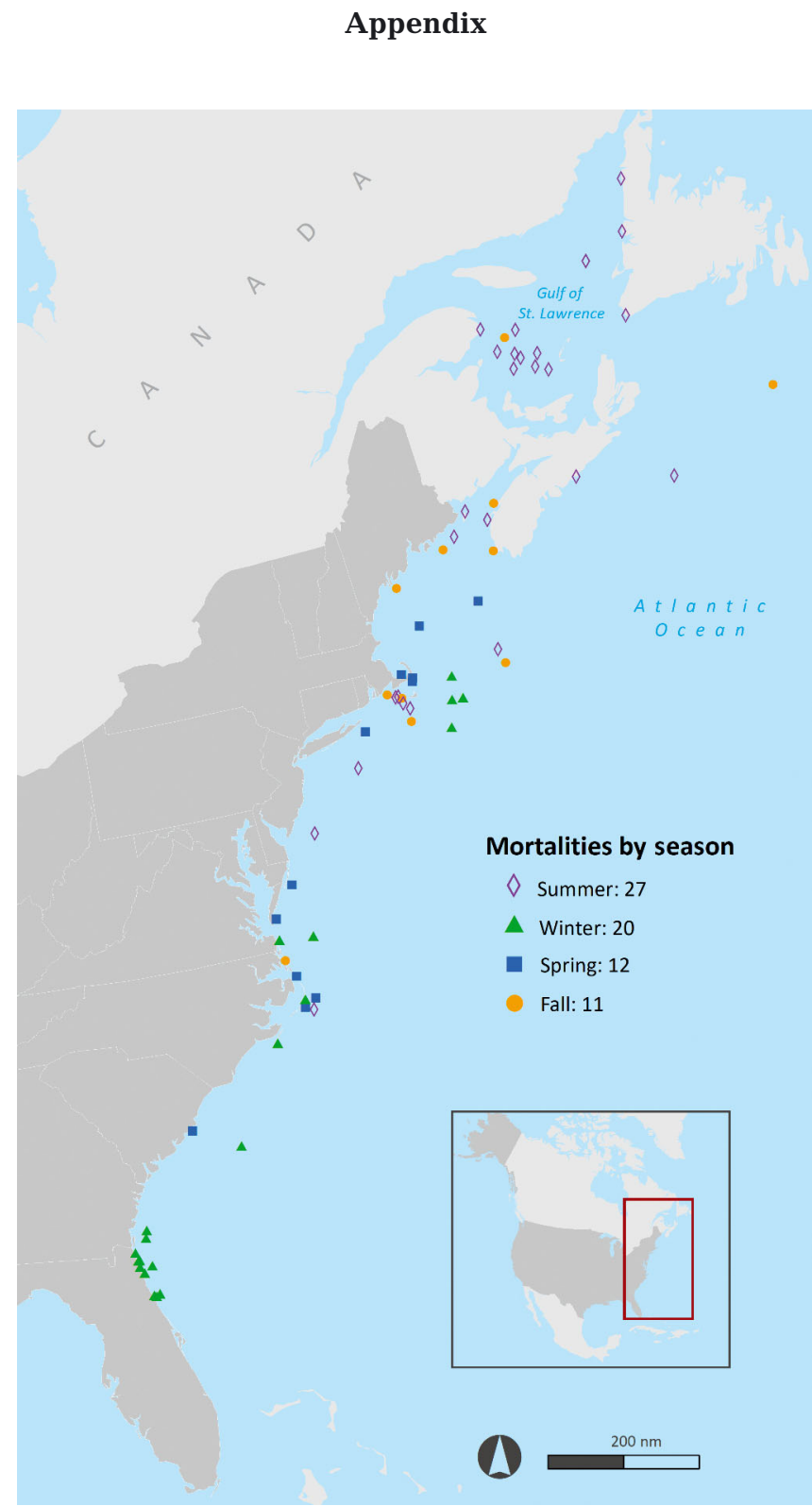

Fig. A1. North Atlantic right whale mortalities $(n=70)$ between 2003 and 2018 by season. Seasons are defined as follows: spring: March-May; summer: June-August; fall: September-November; winter: December-February

Editorial responsibility: Stephen Raverty, Abbotsford, British Columbia, Canada
Submitted: March 7, 2019; Accepted: April 1, 2019

Proofs received from author(s): July 4, 2019 